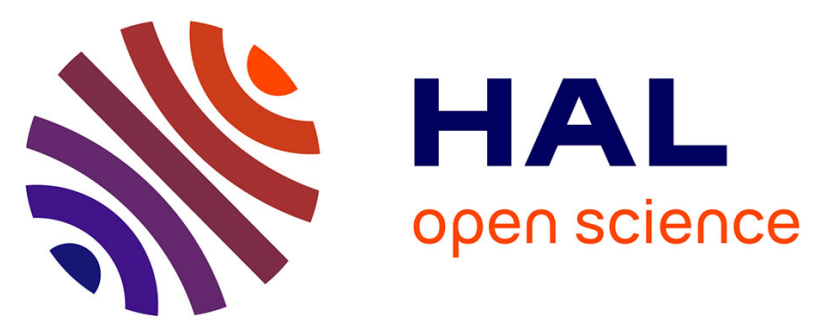

\title{
Kinetics and mechanism of the dehydration of calcium sulfate dehydrate: a comprehensive approach for the dehydration of ionic hydrates under controlled temperature and water vapor pressure
}

\author{
João G. D. Preturlan, Laetitia Vieille, Sara Quiligotti, Loïc Favergeon
}

\section{To cite this version:}

João G. D. Preturlan, Laetitia Vieille, Sara Quiligotti, Loïc Favergeon. Kinetics and mechanism of the dehydration of calcium sulfate dehydrate: a comprehensive approach for the dehydration of ionic hydrates under controlled temperature and water vapor pressure. Journal of Physical Chemistry C, 2020, 124 (48), pp.26352 à 26367. 10.1021/acs.jpcc.0c09041 . emse-03113546

HAL Id: emse-03113546

https://hal-emse.ccsd.cnrs.fr/emse-03113546

Submitted on 15 Mar 2021

HAL is a multi-disciplinary open access archive for the deposit and dissemination of scientific research documents, whether they are published or not. The documents may come from teaching and research institutions in France or abroad, or from public or private research centers.
L'archive ouverte pluridisciplinaire HAL, est destinée au dépôt et à la diffusion de documents scientifiques de niveau recherche, publiés ou non, émanant des établissements d'enseignement et de recherche français ou étrangers, des laboratoires publics ou privés. 
Kinetics and Mechanism of the Dehydration of Calcium Sulfate Dihydrate: a Comprehensive Approach for Studying the Dehydration of Ionic Hydrates Under Controlled Temperature and Water Vapor Pressure

João G. D. Preturlan ${ }^{\mathrm{a}, \mathrm{b}}$, Laetitia Vieille ${ }^{\mathrm{a}}$, Sara Quiligotti ${ }^{\mathrm{b}}$, Loïc Favergeon ${ }^{\mathrm{a},{ }^{*}}$

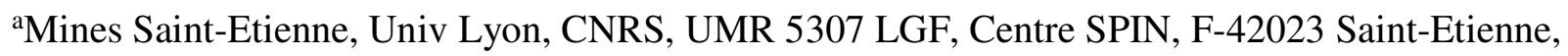

France

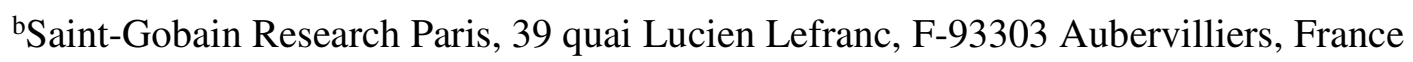

*E-mail: favergeon@emse.fr

Telephone number: +33 (0)4 77420293

Address: Mines Saint-Etienne, Univ Lyon, CNRS, UMR 5307 LGF, Centre SPIN, F-42023

Saint-Etienne, France 


\begin{abstract}
We studied the kinetics and mechanism of the dehydration reaction of calcium sulfate dihydrate to hemihydrate under controlled temperature and water vapor partial pressure. From kinetic and reaction rate curves obtained using TGA under isothermal and isobaric conditions, we determined the overall behavior of this dehydration reaction and the effects of the system's intensive variables on its kinetics. We observed that the reactions take place with an initial induction period that decreases with increasing temperature, followed by a sigmoidal mass loss controlled by both nucleation and growth processes. Characterization of our samples at different instants of the reaction allowed us to observe and confirm a surface nucleation process followed by isotropic growth of the nuclei with inward development of the solid product. We then employed the Mampel kinetic model based on the observed experimental results considering the physical nature of the investigated transformation and the real geometry of the particles. Form this model, we obtained sets of kinetic parameters for the nucleation and growth processes and their evolution with temperature. We then proposed physicochemical mechanisms for both processes, and they were considered to interpret the kinetic parameters obtained previously. This mechanistic analysis of the system allowed determining the effects of both temperature and water vapor pressure on the kinetic behavior of the reaction, which corresponds to a novel approach for the dehydration reaction of calcium sulfate dihydrate. The use of this universal kinetic approach to treat this chemical system. The methodology used in this work can be applied for studying the dehydration of other ionic hydrates.
\end{abstract}




\section{INTRODUCTION}

Many essential processes in modern chemical and material synthesis industries involve the thermal dehydration of crystalline solids. The products of such processes are necessary for many fields such as construction materials ${ }^{1-6}$, production of solar panels ${ }^{7}$, and thermochemical energy storage $^{8-11}$. These types of solid-gas reactions can typically be represented by the following chemical equation

$$
\mathrm{S} \cdot(\mathrm{n}+\mathrm{p}) \mathrm{H}_{2} \mathrm{O}_{(\mathrm{s})} \rightleftharpoons \mathrm{S} \cdot \mathrm{pH}_{2} \mathrm{O}_{(\mathrm{s})}+\mathrm{nH}_{2} \mathrm{O}_{(\mathrm{g})}
$$

where $\mathrm{S}$ in an ionic compound, $\mathrm{n}>0$, and $\mathrm{p} \geq 0$. For these kinds of decompositions reactions, the partial pressure of the generated gases has an effect on the overall reaction kinetics for a large number of chemical systems. ${ }^{12-21}$ Nevertheless, the studies considering, measuring, and controlling the partial pressure of generated gases are relatively rare among all the published studies in the kinetics of solid-gas reactions. Indeed in the case of thermal decomposition of solids, both the selfgenerated and the atmospheric gas partial pressure are responsible for determining the overall kinetic behaviors, and the experimental control of the self-generated pressure is a great challenge. A recent work reveals the variations in the reaction pathways and kinetics behaviors with the selfgenerated water vapor pressure conditions in the case of the thermal dehydration of calcium sulfate dehydrate. $^{22}$

Another possible reason for this gap in the literature is likely to be related to the fact that most of the current literature in heterogeneous reaction kinetics uses the following expression to express reaction rate

$$
\frac{\mathrm{d} \alpha}{\mathrm{dt}}=\mathrm{A} \exp \left(-\frac{\mathrm{E}}{\mathrm{RT}}\right) \mathrm{f}(\alpha)
$$


where $A$ is the pre-exponential factor, $E$ is the apparent activation energy, and $f(\alpha)$ is a kinetic law as listed by Sharp et al. ${ }^{23}$ The drawbacks behind this simplistic approach to express reaction rate have been systematically highlighted and explained by authors such as Galwey et al., Pijolat et al., Koga, and Soustelle. ${ }^{24-31}$ One of these issues with this approach is that Eq. (2) does not consider the kinetic effect of any intensive thermodynamic parameter other than the temperature and assumes an Arrhenius-type dependence for this parameter without any experimental verification. This approach can then lead to misconceptions regarding the studied reaction because, for instance, if gases are consumed or produced during a chemical transformation, their partial pressures are likely to influence the kinetics of the process. To mitigate this issue for dehydration reactions, some authors introduce a function $\mathrm{a}\left(\mathrm{P}_{\mathrm{H}_{2} \mathrm{O}}, \mathrm{P}_{\mathrm{eq}}(\mathrm{T})\right)$ of the water vapor pressure of the system $\mathrm{P}_{\mathrm{H}_{2} \mathrm{O}}$ and the equilibrium pressure for the reaction $\mathrm{P}_{\mathrm{eq}}(\mathrm{T})$ to accommodate the water vapor partial pressure in the reaction rate expression ${ }^{21,32,33}$

$$
\frac{\mathrm{d} \alpha}{\mathrm{dt}}=\mathrm{A} \exp \left(-\frac{\mathrm{E}}{\mathrm{RT}}\right) \mathrm{f}(\alpha) \mathrm{a}\left(\mathrm{P}_{\mathrm{H}_{2} \mathrm{O}}, \mathrm{P}_{\mathrm{eq}}(\mathrm{T})\right)
$$

(3)

where this accommodation function is customarily considered to have the following classical form $^{34-37}$

$$
\mathrm{a}\left(\mathrm{P}_{\mathrm{H}_{2} \mathrm{O}}, \mathrm{P}_{\mathrm{eq}}(\mathrm{T})\right)=1-\frac{\mathrm{P}_{\mathrm{H}_{2} \mathrm{O}}}{\mathrm{P}_{\mathrm{eq}}(\mathrm{T})}
$$


These ways of expressing the accommodation function have been derived by considering the contribution of the reverse reaction on the overall reaction rate. For this reason, the equilibrium pressure $\mathrm{P}_{\mathrm{eq}}(\mathrm{T})$ is then related to the overall equilibrium constant $\mathrm{K}_{\mathrm{eq}}(\mathrm{T})$ of the reaction, expressed in $\mathrm{hPa}$, according to the following relationship

$$
\mathrm{K}_{\mathrm{eq}}(\mathrm{T})=\exp \left(-\frac{\Delta_{\mathrm{r}} \mathrm{G}^{\circ}}{\mathrm{RT}}\right)=\frac{\mathrm{P}_{\mathrm{eq}}(\mathrm{T})}{P^{\circ}}
$$

where $\Delta_{\mathrm{r}} \mathrm{G}^{\circ}$ is the changes in Gibbs free energy of reaction at standard conditions, $\mathrm{R}$ is the ideal gas constant, $\mathrm{T}$ is the absolute temperature in $\mathrm{K}$, and $P^{\circ}$ is the reference pressure equal to $1013.25 \mathrm{hPa}$.

Although useful to represent the pressure influence for many systems, different authors have observed that this classical form of the accommodation function given by Eq. (4) may not be sufficient to express the entire partial pressure dependences for the kinetic rate laws of different solid-gas reactions. Thorough studies of solid-gas reactions mechanisms have shown a variety of possible laws expressing the physicochemical relationship between reaction rate and the partial pressure of reactive gases. ${ }^{16,18,38-44}$ For some of these expressions, the temperature and pressure dependences are not separable as implied by Eq. (3). More recently, a more general accommodation function with two $\mathrm{P}_{\mathrm{H}_{2} \mathrm{O}}$ components has been obtained from the classical nucleation and interface reaction theories and applied to the formal kinetics analyses for the thermal decomposition of calcium hydroxide ${ }^{18}$ and copper hydroxide ${ }^{21}$. These methods were then employed to thoroughly study the thermal decomposition of lithium sulfate monohydrate ${ }^{33}$ and magnesium hydroxide ${ }^{32}$.

In this context, if we want to perform a thorough study of a solid-gas reaction, we need to consider several aspects such as the physics of the specific transformation, the changes undergone by the sample, performing a fairly substantial number of experiments, and studying its mechanism. 
In this work, we apply this methodology for a chemical reaction that is of paramount importance for the materials construction industry: the dehydration of gypsum to produce plaster.

Gypsum is the mineralogical term for minerals that are mainly constituted by calcium sulfate dihydrate $\left(\mathrm{CaSO}_{4} \cdot 2 \mathrm{H}_{2} \mathrm{O}\right)$. The partial dehydration of this material by calcination processes produces plaster (of Paris) that is mainly constituted of calcium sulfate hemihydrate $\left(\mathrm{CaSO}_{4}\right.$. $0.5 \mathrm{H}_{2} \mathrm{O}$ ). Plaster, in turn, is widely industrially produced and one of the most used construction materials in modern society. ${ }^{4}$ Due to the importance of these compounds, many authors have studied the reactivity and kinetics of the chemical system composed of $\mathrm{CaSO}_{4} \cdot 2 \mathrm{H}_{2} \mathrm{O}$ and $\mathrm{CaSO}_{4}$. $0.5 \mathrm{H}_{2} \mathrm{O}$. However, in this extensive amount of published works we observe very little agreement regarding the kinetic model (rate law expressions), kinetic constants (pre-exponential factors and apparent activation energy values), and methodologies to study reaction kinetics.

To illustrate these issues, Table S1 in the Supporting Information lists a summary of some of the available results currently found in the literature regarding the kinetics of the dehydration reaction of $\mathrm{CaSO}_{4} \cdot 2 \mathrm{H}_{2} \mathrm{O}$. 
Most studies seem to agree on the fact that the temperature dependence on the reaction rate obeys the Arrhenius law. However, the reported values of pre-exponential factors and apparent activation energy can vary considerably between studies. For instance, for the same transformation, Ball and Norwood ${ }^{14}$ report $41.0 \mathrm{~kJ} \cdot \mathrm{mol}^{-1}$ while Strydom et al. ${ }^{45}$ calculate values up to $392 \mathrm{~kJ}$. $\mathrm{mol}^{-1}$. Another issue is that for many studies we observe that the apparent activation energy values vary with parameters such as the fractional conversion or water vapor pressure. ${ }^{14,46-48}$ This observation contradicts the initial assumption of Arrhenius law dependence (for which the activation energy is constant), lacks physical meaning, and may reflect an inadequate choice of kinetic models. ${ }^{26-28}$

Regarding the water vapor partial pressure, relatively few studies considered the influence of this parameter on reaction kinetics, and the general conclusions do not find a consensus about its effect on reaction kinetics. Some authors reported that this parameter could cause variation in the apparent activation energy values. ${ }^{14,47}$ Ball and Urie reported having observed the SmithTopley effect for the dehydration of hemihydrate. ${ }^{46}$ Cave and Holdich reported experimental results showing that increasing water vapor partial pressure could reduce the dehydration rate of DSG gypsum. ${ }^{49}$ Liavitskaya and Vyazovkin considered this parameter in their modeling, but no precise measurement of this parameter and its effects on kinetics has been reported. ${ }^{36}$

Another aspect that we observe in the literature is the recurrent use of the JMAEK model to represent the kinetic curves. It has been argued that this class of models lacks physical meaning for solid-gas reactions. ${ }^{26-28}$ Solid-gas reactions take place due to two fundamental processes: surface nucleation and growth. ${ }^{31,50}$ The hypotheses made by Avrami ${ }^{51-53}$ for the development of these models comprise bulk nucleation in an infinite volume sample. Therefore, it does not represent the actual physics for solid-gas reactions and is then not adapted for such a class of reactions. 
For all these reasons, the present work intends to make a contribution by providing a comprehensive kinetic study of the dehydration reaction of $\mathrm{CaSO}_{4} \cdot 2 \mathrm{H}_{2} \mathrm{O}$. Therefore, we study the dehydration reaction of this solid taking into account the different intensive and extensive variables that may play a role in its dehydration reaction. We obtain kinetic data by TGA under isothermal and isobaric conditions. We also perform a set of characterization experiments to assess the different aspects of the solid throughout the dehydration process. Therefore, a physically based kinetic model is then proposed, and the fitted kinetic parameters are critically analyzed. Finally, we propose mechanisms for both nucleation and growth processes in order to propose a molecular interpretation of the dehydration reaction. This method of studying solid-gas reactions can be applied to other ionic hydrates.

\section{MATERIALS AND METHODS}

\subsection{Materials}

The primary source of calcium sulfate for this study was a sample of reagent grade calcium sulfate dihydrate (purity $>99.9 \%$, Sigma-Aldrich, CAS:10101-41-4) in powder form. This sample was sieved and the fraction between $20 \mu \mathrm{m}$-mesh and $50 \mu \mathrm{m}$-mesh was selected for the experiments. To characterize the nucleation and growth processes, we also employed monocrystalline transparent samples of natural gypsum (selenite, from France).

\subsection{Characterization Techniques}

We determined the morphology, size distribution, and the nucleation/growth modes of the calcium sulfate dihydrate samples by scanning electron microscopy (SEM; SUPRA 55VP, Setaram). The surface of the natural gypsum samples was also observed after dehydration by optical microscopy (SZX9, Olympus). 
The powder X-ray patterns of the sample $\left(10^{\circ} \leq 2 \theta \leq 32^{\circ}\right)$ were measured in-situ throughout the dehydration reaction under controlled temperature $\mathrm{T}$ and water vapor partial

pressure $\mathrm{P}_{\mathrm{H}_{2} \mathrm{O}}$ conditions using a Bruker D8 Advance diffractometer $\left(\mathrm{Cu}-\mathrm{K}_{\alpha}\right.$ monochromatic radiation, $\lambda=1.5406 \AA$, scan time of $2 \mathrm{~s}, 2 \theta$-step of $0.023^{\circ}$ ). To this end, the powder sample was placed in a closed chamber instrumented with an automated humidity generator (Wetsys, Setaram). We used a mixture of Helium and water vapor $\left(67 \mathrm{~cm}^{3} \cdot \mathrm{min}^{-1}, \mathrm{P}_{\mathrm{H}_{2} \mathrm{O}}=20 \mathrm{hPa}\right)$ as carrier gas. The results were compared to the patterns of calcium sulfate dihydrate (Powder Diffraction File (PDF) no. 33-0311, Joint Committee on Powder Diffraction Standards (JCPDS), [1980]) and hemihydrate (PDF no. 41-0224, JCPDS, [1989]). We also verified the elemental composition of the initial calcium sulfate dihydrate sample by inductive coupled plasma spectrometry (ICP-MS, JY 138 Ultratrace, ISA Jobin Yvon).

The specific surface area and the pore size distribution were measured from nitrogen adsorption data at $77 \mathrm{~K}$ (ASAP 2020, Micromeritics). The adsorption data were obtained for the relative pressure range between 0.005 and 0.99. The data were treated with the Brunauer-EmmetTeller (BET) theory to estimate the BET area of the samples and the Barret, Joyner, and Halenda (BJH) method to estimate the pore size distribution. ${ }^{54-56}$

\subsection{Kinetic Data Measurements by Thermogravimetric Analysis}

The kinetic data were obtained using thermogravimetric analysis (TGA) at isotherm and isobaric conditions. The experiments were carried out using a symmetrical thermobalance (TAG 16 , Setaram, precision of $10^{-3} \mathrm{mg}$ ) instrumented with an automated humidity generator (Wetsys, Setaram). The experiments were performed under atmospheric pressure with a constant flowing mixture of Helium and water vapor as carrier gas $\left(50 \mathrm{~cm}^{3} \cdot \mathrm{min}^{-1}\right.$, the residual moisture of the dry Helium was inferior to $100 \mathrm{ppm}$ ). The use of Helium is preferable because of its high thermal 
conductibility, which reduces the perturbation of the mass signal during the TGA experiments. ${ }^{57}$ The thermobalance has two parallel furnaces in which we place at the same time and under the same conditions one empty crucible (reference) and another crucible filled with the sample. Therefore, this dual furnace apparatus prevents buoyancy effect perturbations (blank tests are not necessary) and the total carrier gas flow rate is divided equally between these two furnaces $\left(25 \mathrm{~cm}^{3} \cdot \min ^{-1}\right.$ each $)$.

The experiments were carried out at total atmospheric pressure. Therefore, the water vapor pressure values in this work correspond to partial pressure values (represented by $\mathrm{P}_{\mathrm{H}_{2} \mathrm{O}}$ ). The isothermal and isobaric mass loss data were recorded in the ranges $361 \mathrm{~K} \leq T \leq 383 \mathrm{~K}$ and $20 \mathrm{hPa} \leq \mathrm{P}_{\mathrm{H}_{2} \mathrm{O}} \leq 60 \mathrm{hPa}$. The initial calcium sulfate dihydrate powder quantities for the experiments were of $(5.0 \pm 1.5) \mathrm{mg}$. We used quartz crucibles as sample holders with a diameter of $9 \mathrm{~mm}$ and with a fritted glass bottom, which is porous and allows the gas to pass through and be in contact with the inferior part of the powder bed. The quantity of powder was sufficiently reduced so that the sample was dispersed in the crucible's fritted bottom without the formation of a significant layer, minimizing effects of heat and mass transfer. ${ }^{5,58}$

For the pseudo-steady state test $\mathrm{t}^{24}$, coupled measurements of mass loss and heat flow were performed using Thermogravimetry (TG) - Differential Scanning Calorimetry (DSC) (SENSYS EVO TG-DSC, Setaram). This apparatus allows simultaneous measurements by TGA and DSC. These experiments were also performed with a flowing mixture of Helium and water vapor $\left(20 \mathrm{~cm}^{3} \cdot \mathrm{min}^{-1}\right)$, and the water vapor partial pressure was controlled using an automated humidity generator (Wetsys, Setaram). This experimental apparatus has two symmetrical furnaces that allows placing one reference crucible (empty) and one filled crucible simultaneously. The initial calcium sulfate dihydrate powder quantities for the experiments were of $(2.5 \pm 0.5) \mathrm{mg}$. The 
sample holder was a quartz crucible with an internal diameter of $2 \mathrm{~mm}$, an internal depth of $5 \mathrm{~mm}$, and with a fritted glass bottom. The experimental conditions were also optimized to minimize the effects of heat and mass transfer on reaction kinetics.

\section{RESULTS AND DISCUSSION}

\subsection{Initial Sample Characterization}

Figure 1 shows the particles SEM images of the synthetic calcium sulfate dihydrate powder. We observe that their surfaces are considerably smooth. Regarding their symmetry, they can be represented by parallel-sided slabs. The particle size distribution and the methods for obtaining these dimensions are detailed in the Supporting Information. The histograms for particle size are shown in Figure S1. 

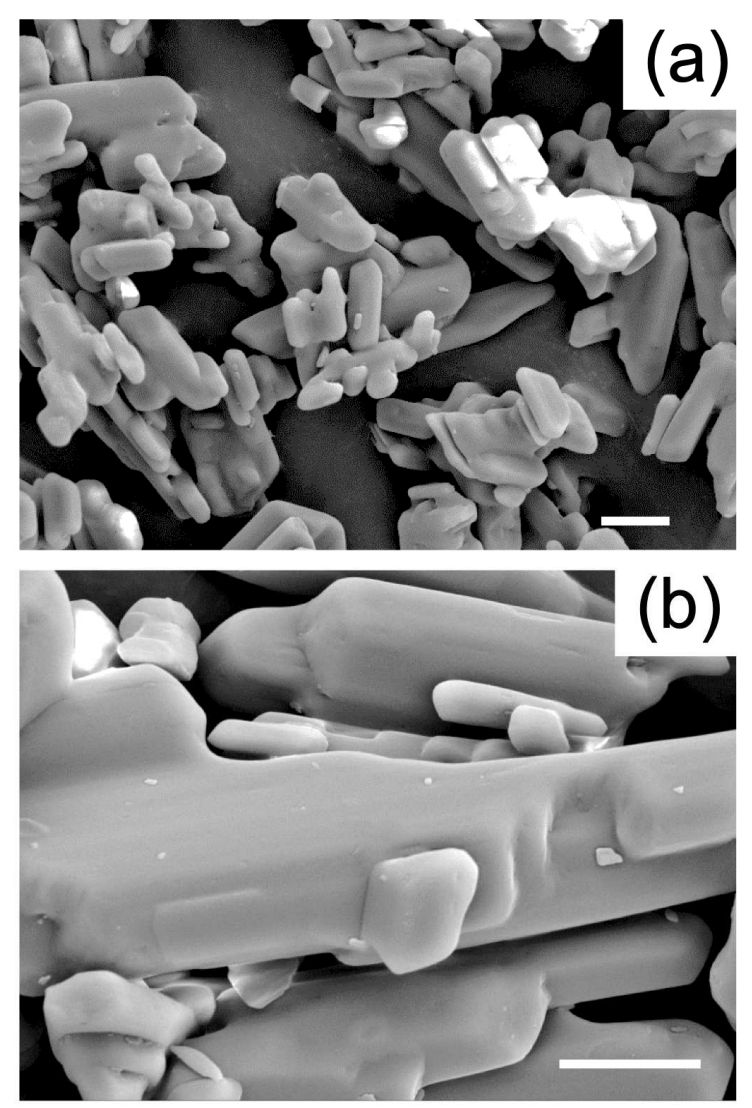

Figure 1. (a) SEM images of the calcium sulfate dihydrate powder's particles. (b) SEM image illustrating the smooth surface of the particles before the dehydration reaction (scale bars $=10 \mu \mathrm{m}$ ).

We have also characterized the initial sample for its texture, porosity, chemical composition, and crystalline phase composition. Figure $\mathrm{S} 2$ in the supporting information file shows the nitrogen adsorption isotherm at $77 \mathrm{~K}$. We obtained a type II isotherm according to the Brunauer, Deming, and Deming and Teller (BDDT) classification with negligible hysteresis, which is typical of nonporous materials. ${ }^{56}$ We calculated a BET specific surface area of $(0.4 \pm 0.1) \mathrm{m}^{2} / \mathrm{g}$. Table $\mathrm{S} 2 \mathrm{in}$ the Supporting Information shows the element composition of the calcium sulfate dihydrate sample by ICP-MS. The semi-quantitative concentrations of calcium and sulfur obtained corresponded to their stoichiometric quantities in $\mathrm{CaSO}_{4} \cdot 2 \mathrm{H}_{2} \mathrm{O}$ with less than $1 \%$ variation and other elements were present in considerably lower concentration or as traces. Figure S3 shows the X-ray diffractogram of the initial sample. The only identified compound was $\mathrm{CaSO}_{4} \cdot 2 \mathrm{H}_{2} \mathrm{O}$ in the 
detection limit (PDF no. 33-0311, JCPDS, [1980]). These combined results along with further thermal analysis allow confirming the nature of the initial sample.

\subsection{Overall Behavior of the Sample During Dehydration}

Figure 2 shows the results for dehydration experiments of the initial sample under isothermal and isobaric TGA. Figure 2a shows the relative mass loss curves for the dehydration reactions at constant $\mathrm{T}=373 \mathrm{~K}$ and distinct $\mathrm{P}_{\mathrm{H}_{2} \mathrm{O}}$ values, and Figure $2 \mathrm{~b}$ shows similar curves but for constant $\mathrm{P}_{\mathrm{H}_{2} \mathrm{O}}=20 \mathrm{hPa}$ and distinct $\mathrm{T}$. First of all, we observe that according to the $\left(\mathrm{T}, \mathrm{P}_{\mathrm{H}_{2} \mathrm{O}}\right)$ conditions under which the reaction was carried out, the final relative mass losses seem to be concentrated in two zones. One group of curves $(1,2,3,6,7$, and 8 ) shows a relative mass loss close to $-15.7 \%$, which corresponds to the dehydration reaction of $\mathrm{CaSO}_{4} \cdot 2 \mathrm{H}_{2} \mathrm{O}$ producing $\mathrm{CaSO}_{4} \cdot 0.5 \mathrm{H}_{2} \mathrm{O}$ as represented by the following chemical equation

$$
\mathrm{CaSO}_{4} \cdot 2 \mathrm{H}_{2} \mathrm{O}_{(\mathrm{s})} \rightarrow \mathrm{CaSO}_{4} \cdot 0.5 \mathrm{H}_{2} \mathrm{O}_{(\mathrm{s})}+1.5 \mathrm{H}_{2} \mathrm{O}_{(\mathrm{g})}
$$

(6)

On the other hand, the second group of curves (curves 4 and 5) shows values comparable to the stoichiometric values of the complete dehydration of calcium sulfate dihydrate, i.e., $-20.9 \%$. Therefore, this indicates that for the $\left(\mathrm{T}, \mathrm{P}_{\mathrm{H}_{2} \mathrm{O}}\right)$ conditions of curves 4 and 5, the dehydration process takes place as a sequence of two chemical reactions. First, $\mathrm{CaSO}_{4} \cdot 2 \mathrm{H}_{2} \mathrm{O}$ dehydrates to form $\mathrm{CaSO}_{4} \cdot 0.5 \mathrm{H}_{2} \mathrm{O}$ according to Eq. (6). Second, $\mathrm{CaSO}_{4} \cdot 0.5 \mathrm{H}_{2} \mathrm{O}$ dehydrates subsequently to produce the anhydrous form $\mathrm{AIII}-\mathrm{CaSO}_{4}$ (also known as soluble anhydrite or $\gamma$-CaSO${ }_{4}$ ) according to the following chemical reaction

$$
\mathrm{CaSO}_{4} \cdot 0.5 \mathrm{H}_{2} \mathrm{O}_{(\mathrm{s})} \rightarrow{\mathrm{AIII}-\mathrm{CaSO}_{4}(\mathrm{~s})}+0.5 \mathrm{H}_{2} \mathrm{O}_{(\mathrm{g})}
$$




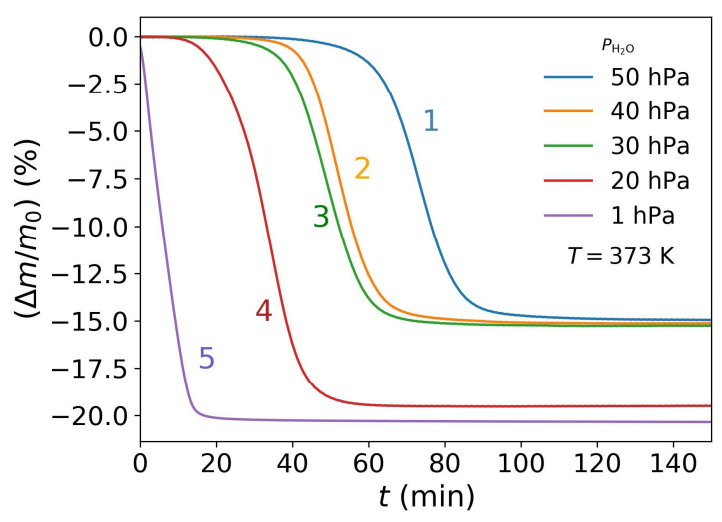

(a)

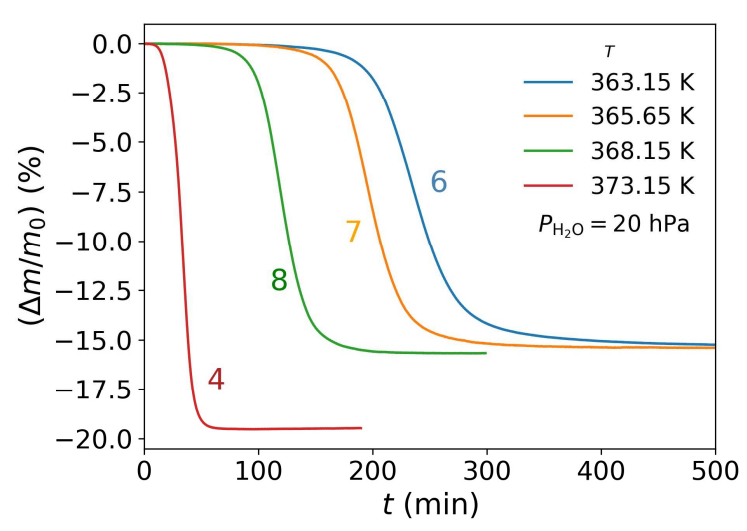

(b)

Figure 2. TGA curves for the dehydration of the calcium sulfate dihydrate sample at constant $\mathrm{T}$ and $\mathrm{P}_{\mathrm{H}_{2} \mathrm{O}}$ conditions: (a) $\mathrm{T}$ effect at constant $\mathrm{P}_{\mathrm{H}_{2} \mathrm{O}}=20 \mathrm{hPa}$ and (b) $\mathrm{P}_{\mathrm{H}_{2} \mathrm{O}}$ effect at constant $\mathrm{T}=373 \mathrm{~K}$. (The red curve identified by for $\mathrm{P}_{\mathrm{H}_{2} \mathrm{O}}=20 \mathrm{hPa}$ and $\mathrm{T}=373 \mathrm{~K}$ appears in both plots.)

The present study's focus was to study only the first step of the gypsum dehydration process as represented by Eq. (6). Therefore, the experiments $\left(T, \mathrm{P}_{\mathrm{H}_{2} \mathrm{O}}\right)$ conditions were concentrated in the phase stability domain of $\mathrm{CaSO}_{4} \cdot 0.5 \mathrm{H}_{2} \mathrm{O}$, as represented in Figure S4. ${ }^{5,59,60}$ The experimental conditions were relatively far from the equilibrium curve corresponding to the reaction in Eq. (6). Thus, the accommodation function value is expected to be close to one for these experiments. 
Apart from these observations, two main aspects can also be retained from the profiles shown in Figure 2. First of all, the curves profiles are all sigmoidal under isothermal and isobaric conditions. Therefore, we can already expect that the reaction kinetics is governed by the competition of the two fundamental processes of solid-gas reactions: surface nucleation and growth. ${ }^{31}$ Nevertheless, we thoroughly verify this further by employing the appropriate kinetic test. Second, the plotted curves show induction periods $t_{I P}$. That is after the reaction $\left(T, \mathrm{P}_{\mathrm{H}_{2} \mathrm{O}}\right)$ conditions are attained, it takes time for the reaction onset to occur. A slow nucleation process typically causes such a phenomenon. These aspects are also further investigated in the following sections.

Finally, Figure S5 in the Supporting Information also presents the results of an in situ XRay Diffraction (XRD) study of the dehydration reaction. This experiment complements the previous observations by TGA ensuring that the studied reaction studied corresponded to the one represented by Eq. (6).

\subsection{Kinetic and Reaction Rate Curves}

Before considering the kinetic and reaction rate curves for the investigated dehydration reaction, we analyzed the kinetic hypothesis of: (i) pseudo-steady state, (ii) existence of a ratedetermining step, and (iii) model choice. ${ }^{24,26-28}$ This part of the study is essential to the physicochemical development of kinetic models and is presented in the Supporting Information, in section S5 and in Figure S6-8. After that we also verified the repeatability of experiments. Figure S9 in the Supporting Information shows the kinetic and reaction rate curves for three experiments carried at the same conditions. They present a reduced variability experiments confirming the overall repeatability of experiments. Nevertheless, these small variations are taken into account in the following analyses. 
For this study, it was also of paramount importance to work with experimental conditions that allow assessing the intrinsic kinetics of the studied reaction. That is, choosing small enough quantities of sample so that effects that may be produced by thick powder beds may be neglected (heat and mass transfer). ${ }^{58}$ More precisely, the hypothesis of no temperature or pressure gradients within the powder beds can be considered. Figure S10 in the Supporting Information shows initial sample masses inferior to $6.5 \mathrm{mg}$ are required to avoid perturbations in the results. Therefore, sample masses were selected in the range of $(5.0 \pm 1.5) \mathrm{mg}$.

Respecting these criteria, a set of experiments under isothermal and isobaric conditions were performed to analyze the kinetic behavior of the reaction as a function of the intensive variables $\mathrm{T}$ and $\mathrm{P}_{\mathrm{H}_{2} \mathrm{O}}$. Figure 3 shows the effects of increasing $\mathrm{T}$ at constant $\mathrm{P}_{\mathrm{H}_{2} \mathrm{O}}=20 \mathrm{hPa}$ on the kinetic and reaction rate curves. Figure 3 a shows the sigmoidal profile of curves and the existence of induction periods that decrease with increasing $\mathrm{T}$. Figure $3 \mathrm{~b}$ shows that the reaction rate increases with increasing T. In particular for this reaction, narrow $\mathrm{T}$ increments show a notable acceleration effect on reaction rate (e.g., $7 \mathrm{~K}$ of variation produce an almost three-fold increase in the reaction rate).

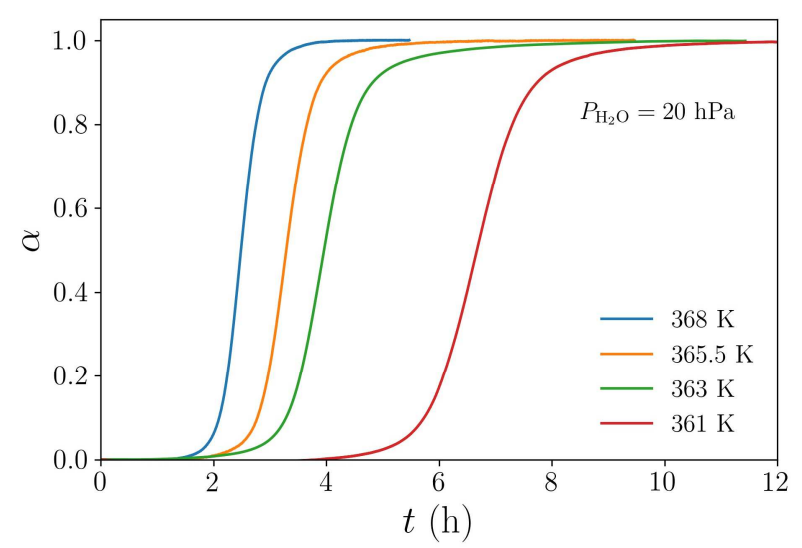

(a) 


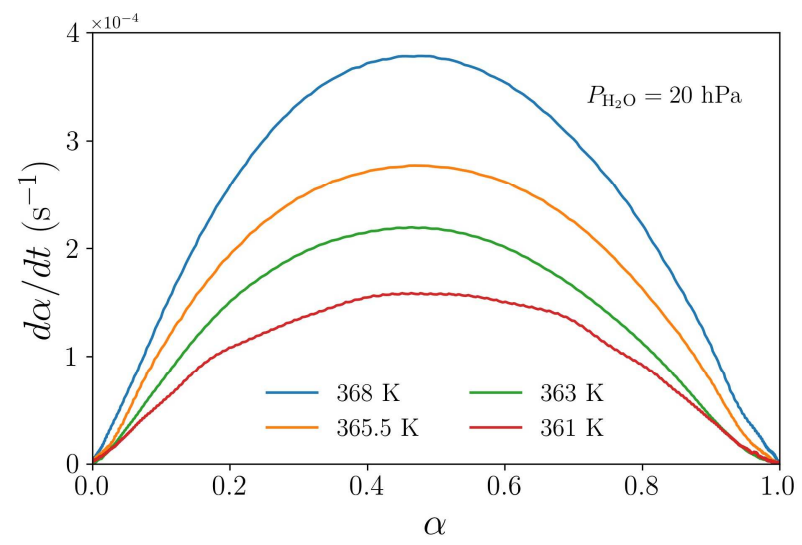

(b)

Figure 3. Kinetic curves showing the influence of the temperature at constant water vapor partial pressure on (a) reaction fractional conversion throughout time and on (b) reaction rate as a function of the fractional conversion.

Figure 4 presents the kinetic and reaction rate curves for different $\mathrm{P}_{\mathrm{H}_{2} \mathrm{O}}$ at constant $\mathrm{T}=$ $373 \mathrm{~K}$. The varying values of $\mathrm{P}_{\mathrm{H}_{2} \mathrm{O}}$ do not seem to change the profiles of the kinetic and reaction rate curves compared to the expected variability for this system shown in Figure S9. The induction period seems to decrease slightly while increasing $\mathrm{P}_{\mathrm{H}_{2} \mathrm{O}}$, however further analysis of this dependence would be necessary to confirm this effect.

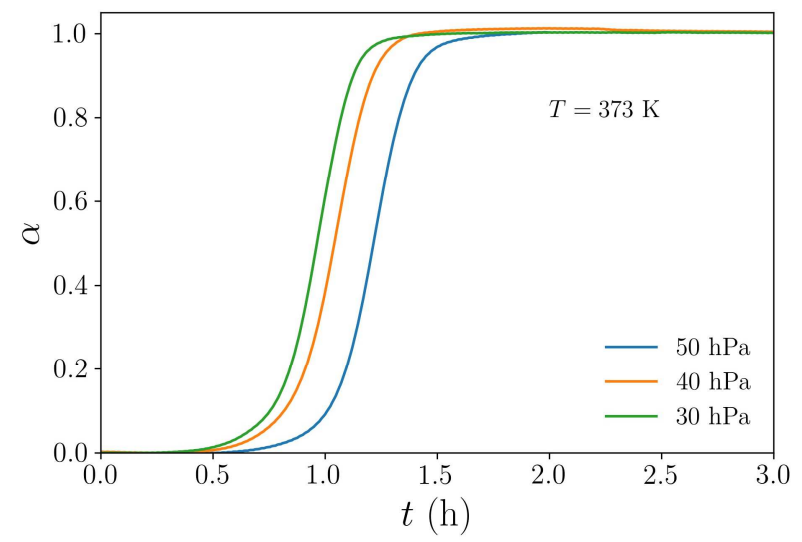

(a) 


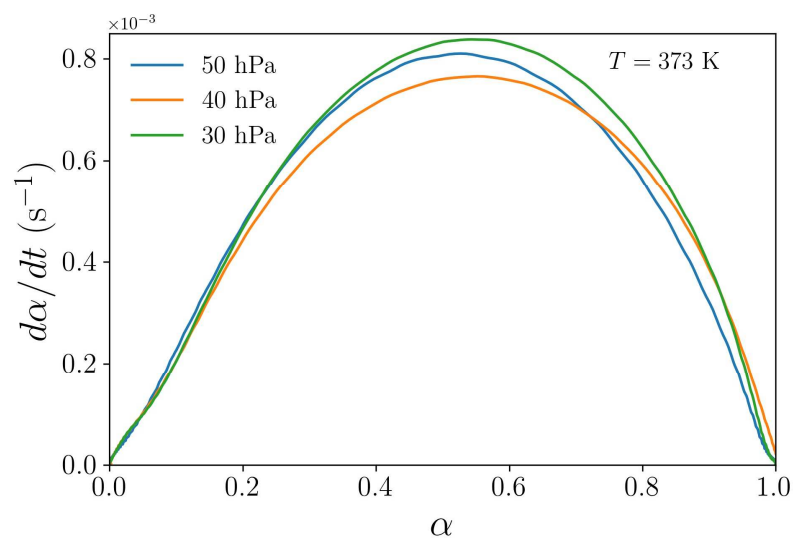

(b)

Figure 4. Kinetic curves showing the influence of the water vapor partial pressure at constant temperature $\mathrm{T}=373 \mathrm{~K}$ : (a) reaction fractional conversion throughout time and on (b) reaction rate as a function of the fractional conversion.

\subsection{Characterization of Nucleation and Growth Processes}

The observation of the sample at different moments of the reaction can contribute to a better understanding of the reaction's fundamental processes: surface nucleation and growth. For example, if we interrupt the reaction at its beginning, i.e., for low values of fractional conversion, it is possible to verify whether nucleation is an "instantaneous" or slow process by microscopic observation. Another possibility, if the reaction continues for more extended periods, we may also be able to observe how the reaction front propagates and how the microstructure of the sample changes with the appearance of cracks or holes.

Figure 5 shows a sequence of SEM images presenting the evolution of the surface of the powder particles during the dehydration reaction. The sample was prepared inside the thermobalance under isothermal and isobaric conditions, and the experiments were interrupted at different fractional conversion values. For the first instants of the reaction, as shown in Figure 5a$\mathrm{b}$, the surface is partially covered with cracks (marked by either the red arrows or the dashed-lined ellipses) whereas the rest of the surfaces remains without any visible cracks. Therefore, the reaction initiates by a slow surface nucleation process (in opposition to instantaneous nucleation). This 
behavior is similar to what has been previously observed for the dehydration of lithium sulfate hydrates. ${ }^{17,33,61}$ When the reaction reaches completion, the cracks and slits cover the surface of the sample entirely as we can observe in Figure 5c-f for two different sets of $\mathrm{T}$ and $\mathrm{P}_{\mathrm{H}_{2} \mathrm{O}}$ conditions. For Figure $5 \mathrm{c}-\mathrm{d}$, we observe the final surface state of grains for a dehydration at $\mathrm{T}=373 \mathrm{~K}$ and $\mathrm{P}_{\mathrm{H}_{2} \mathrm{O}}=40 \mathrm{hPa}$, and for Figure $5 \mathrm{e}-\mathrm{f}, \mathrm{T}=383 \mathrm{~K}$ and $\mathrm{P}_{\mathrm{H}_{2} \mathrm{O}}=20 \mathrm{hPa}$.
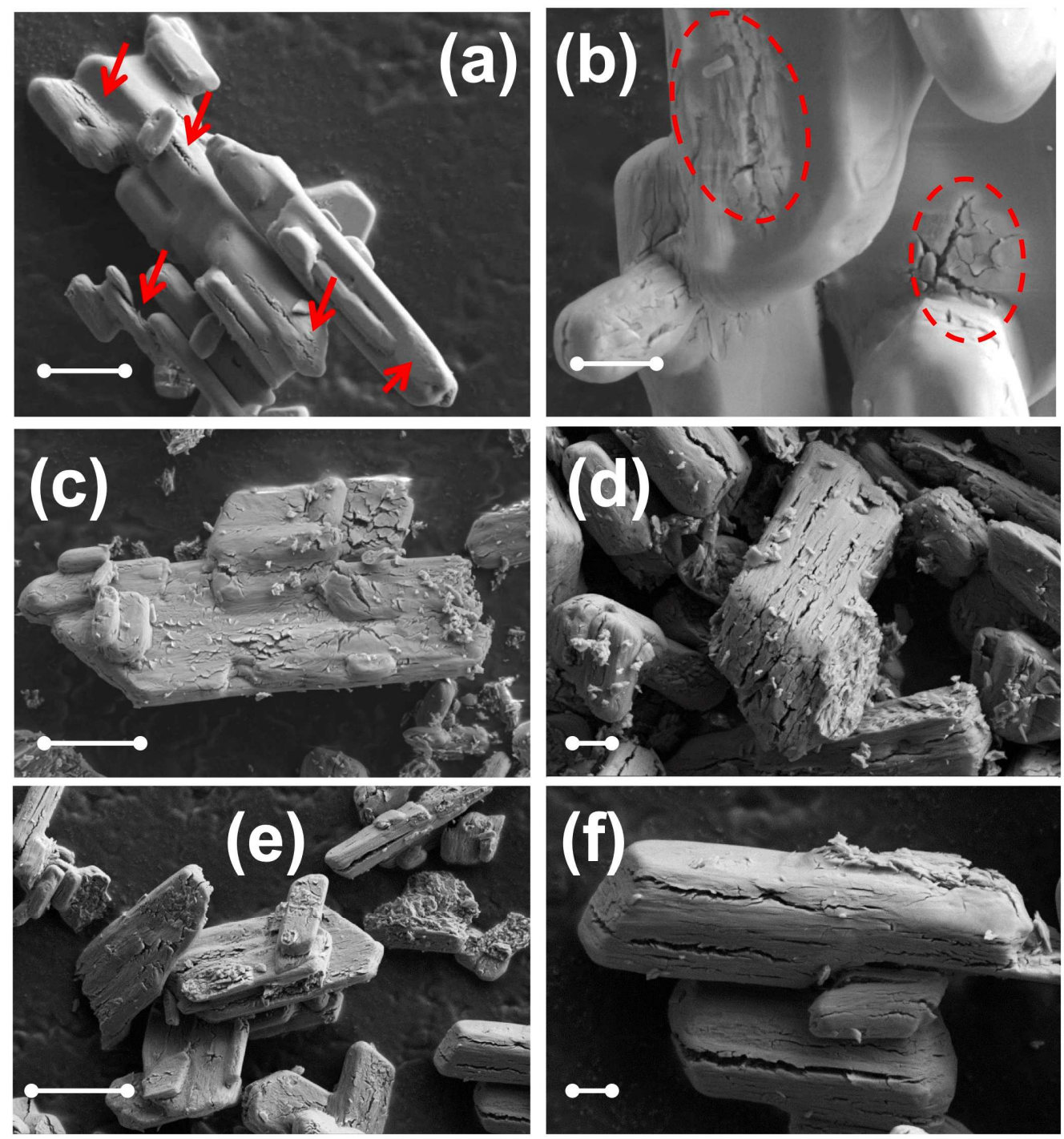

Figure 5. SEM images of the powder showing the changes in texture: (a) and (b) show the beginning of the dehydration reaction with the zones indicating slow nucleation and isotropic growth for the dehydration reaction $\left(\alpha=0.01, \mathrm{~T}=373 \mathrm{~K}, \mathrm{P}_{\mathrm{H}_{2} \mathrm{O}}=40 \mathrm{hPa}\right)$; (c) and (d) show completely dehydrated grains obtained for $\alpha=1, \mathrm{~T}=373 \mathrm{~K}$, and $\mathrm{P}_{\mathrm{H}_{2} \mathrm{O}}=40 \mathrm{hPa}$; (e) and (f) show completely dehydrated grans for $\alpha=1, \mathrm{~T}=$ 
$383 \mathrm{~K}, \mathrm{P}_{\mathrm{H}_{2} \mathrm{O}}=20 \mathrm{hPa}$. The scales bars represent (a) $12 \mu \mathrm{m}$, (b) $2 \mu \mathrm{m}$, (c) $10 \mu \mathrm{m}$, (d) $2 \mu \mathrm{m}$, (e) $12 \mu \mathrm{m}$, and (f) $2 \mu \mathrm{m}$.

A set of natural monocrystalline gypsum samples (selenite) with larger dimensions than the powder particles were also prepared to complement the observations in Figure 5. The same procedure with interrupted dehydration trials was performed at controlled and constant $\mathrm{T}$ and $\mathrm{P}_{\mathrm{H}_{2} \mathrm{O}}$ within the thermobalance. The results for these experiments are shown in Figure 6. Figure 6a shows the surface of a sample dehydrated at $\mathrm{T}=373 \mathrm{~K}$ and $\mathrm{P}=20 \mathrm{hPa}$ for which the dehydration reaction was interrupted at $\alpha=0.02$. The surface, which was initially smooth, starts to crack, forming the quasi-round-shaped domains. This effect is more evident and with higher occurrence rate in Figure $6 \mathrm{~b}$, obtained at $\mathrm{T}=388 \mathrm{~K}, \mathrm{P}=20 \mathrm{hPa}$, and $\alpha=0.06$. Afterward, in order to show how these domains formed at the surface of the sample evolve towards the interior of the sample, the samples were cleaved. Figure 6c-d show SEM images of two cleaved samples. The growth of the reaction product (calcium sulfate hemihydrate) forms spherical caps near the surface of the samples as indicated by the red arrows and dashed lines in Figure 6c, and by the dashed red lines in Figure 6d. Therefore, growth is inward, as generally expected for decomposition reactions. This aspect of the growth process of nuclei was previously observed by X-ray tomography techniques. ${ }^{62,63}$ We also note that growth is isotropic. Moreover, we also confirm that the nucleation takes place exclusively at the surface of the sample. Figure 6e-f shows SEM images of another cleaved selenite sample partially dehydrated at $\mathrm{T}=100^{\circ} \mathrm{C}$ and $\mathrm{P}=40 \mathrm{hPa}$. We confirm the characteristics of the growth process (inward and isotropic), and we can observe an interesting backbone motive created with the dehydration reaction. This microstructure is likely to be formed due to the layered organization of molecules in the structure of calcium sulfate dihydrate. When these molecules exit the samples during dehydration, they leave spaces once occupied and create 
this sort of layered backbone motif inside the sample, as partially observed by Sipple. ${ }^{64}$ Further investigations would be necessary to explain the formation of these patterns in details.
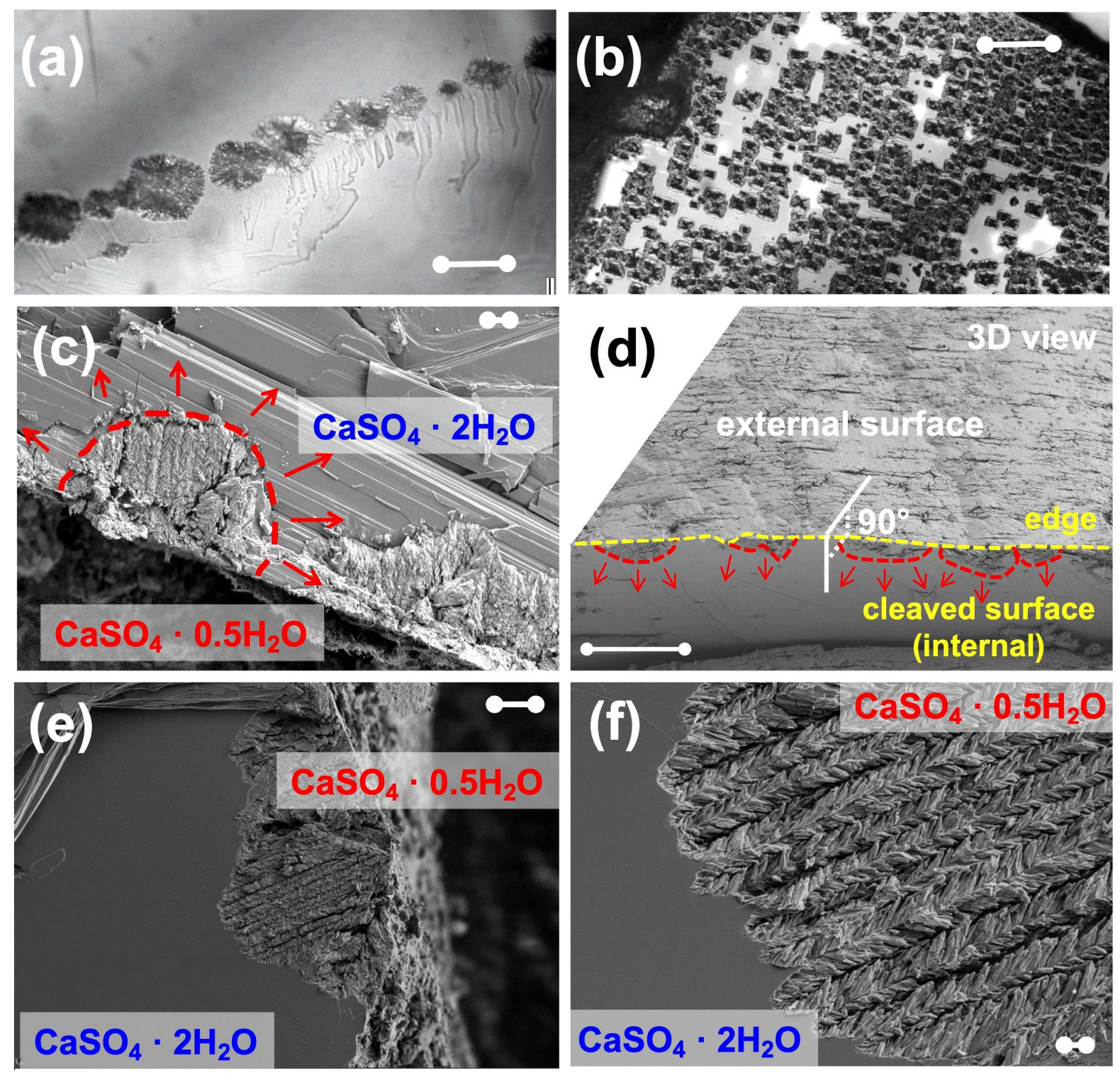

Figure 6. Ex-situ observations of nucleation and growth using natural gypsum: (a) Optical microscope image showing the surface of a sample at $\alpha=0.02\left(\mathrm{~T}=373 \mathrm{~K}, \mathrm{P}_{\mathrm{H}_{2} \mathrm{O}}=20 \mathrm{hPa}\right)$; (b) Optical microscope image showing the surface of a sample at $\alpha=0.06\left(\mathrm{~T}=388 \mathrm{~K}, \mathrm{P}_{\mathrm{H}_{2} \mathrm{O}}=2 \mathrm{hPa}\right)$; (c) SEM micrograph of another sample after cleavage showing the inward and isotropic growth of the phase $\mathrm{CaSO}_{4} \cdot 0.5 \mathrm{H}_{2} \mathrm{O}$; (d) SEM micrograph of a sample after cleavage showing the inward propagation of the reaction front and isotropic growth; (e) Another image of the isotropic inward growth structure showing the backbone structure created by the dehydration of $\mathrm{CaSO}_{4} \cdot 2 \mathrm{H}_{2} \mathrm{O}$; (f) Zoomed view of the backbone structures. The scales bars represent (a) $50 \mu \mathrm{m}$, (b) $200 \mu \mathrm{m}$, (c) $4 \mu \mathrm{m}$, (d) $40 \mu \mathrm{m}$, (e) $10 \mu \mathrm{m}$, and (f) $2 \mu \mathrm{m}$. 


\subsection{Induction Period}

The dehydration process of $\mathrm{CaSO}_{4} \cdot 2 \mathrm{H}_{2} \mathrm{O}$ shows induction periods $\left(\mathrm{t}_{\mathrm{IP}}\right)$ obtained under isothermal and isobaric conditions. Due to the stochastic nature of the nucleation process, this parameter can be challenging to predict. Moreover, the determination of this parameter depends typically on the sensitivity and precision of the experimental measurements. For instance, using a high-performance thermobalance such as a TAG 16 (Setaram) that can detect mass changes of $1 \mu \mathrm{g}$ is likely to give shorter induction periods compared to standard bench thermobalances. Nevertheless, we can consider some empirical and theoretical ways to interpret and predict this parameter.

For the present work, the $t_{I P}$ values are determined as the period necessary to obtain $\alpha=$ 0.01. These values, obtained as a function of the temperature, are shown in Figure 7. Figure 7a shows that this parameter decreases with the temperature, following a trend that has already been observed qualitatively for other dehydration reactions. ${ }^{18,19,33}$ Moreover, due to its nearly exponential profile, it is possible to test the applicability of an Arrhenius-type model of the inverse of the induction period according to the following definition

$$
\frac{1}{\mathrm{t}_{\mathrm{IP}}}=\theta_{0} \exp \left(-\frac{\Theta_{\mathrm{IP}}}{\mathrm{RT}}\right)
$$

(8)

where $\theta_{0}$ is the pre-exponential factor and $\Theta_{\mathrm{IP}}$ is the temperature coefficient. Figure $7 \mathrm{~b}$ shows the Arrhenius plot for this parameter. The linear regression allows estimating $\ln \theta_{0}=50.0$ and $\Theta_{\mathrm{IP}}=$ $179 \mathrm{~kJ} \cdot \mathrm{mol}^{-1}$.

If the Arrhenius law assumption is valid, Koga et al. suggest that the apparent kinetics of the reaction during the induction period can be represented by the following kinetic law ${ }^{19,21,33,65-68}$ 


$$
\frac{\mathrm{d} \alpha_{I P}}{d t}=k_{I P} f\left(\alpha_{I P}\right)
$$

(9)

where:

- $\alpha_{\mathrm{IP}}$ represents the saturation degree of the nuclei-forming site,

- $\mathrm{k}_{\mathrm{IP}}$ is the apparent rate constant that follows the Arrhenius law, as follows

$$
\mathrm{k}_{\mathrm{IP}}=\mathrm{A}_{\mathrm{IP}} \exp \left(-\frac{\mathrm{E}_{\mathrm{IP}}}{\mathrm{RT}}\right)
$$

(10)

- $\mathrm{A}_{\mathrm{IP}}$ and $\mathrm{E}_{\mathrm{IP}}$ are the pre-exponential factor and the apparent activation energy for the IP, respectively,

- $\mathrm{f}\left(\alpha_{\mathrm{IP}}\right)$ is the conversion function.

Considering this formalism, we can rewrite Eq. (9) leading to the following equation (normally referred to as the isoconversional plot expression)

$$
\ln \left(\frac{1}{t_{I P}}\right)=\ln \left[A_{I P} f\left(\alpha_{I P}\right)\right]-\frac{E_{I P}}{R T}
$$

for which the term $A_{I P} f\left(\alpha_{I P}\right)$ is constant. Therefore, following this definition, the previously estimated pre-exponential term $\theta_{0}$ corresponds to the term $A_{I P} f\left(\alpha_{I P}\right)$, which is constant; and the previously estimated temperature coefficient $\Theta_{\mathrm{IP}}$ corresponds to the apparent activation energy for the induction period. 


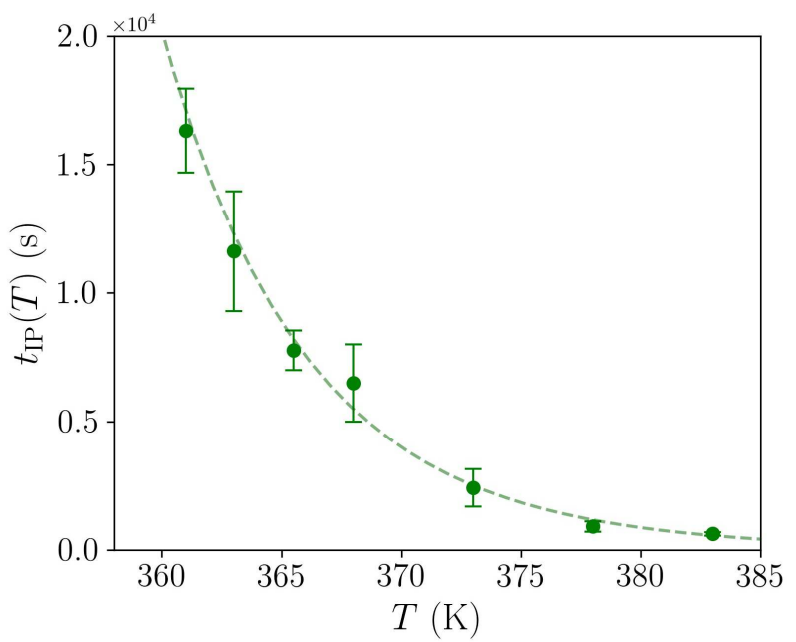

(a)

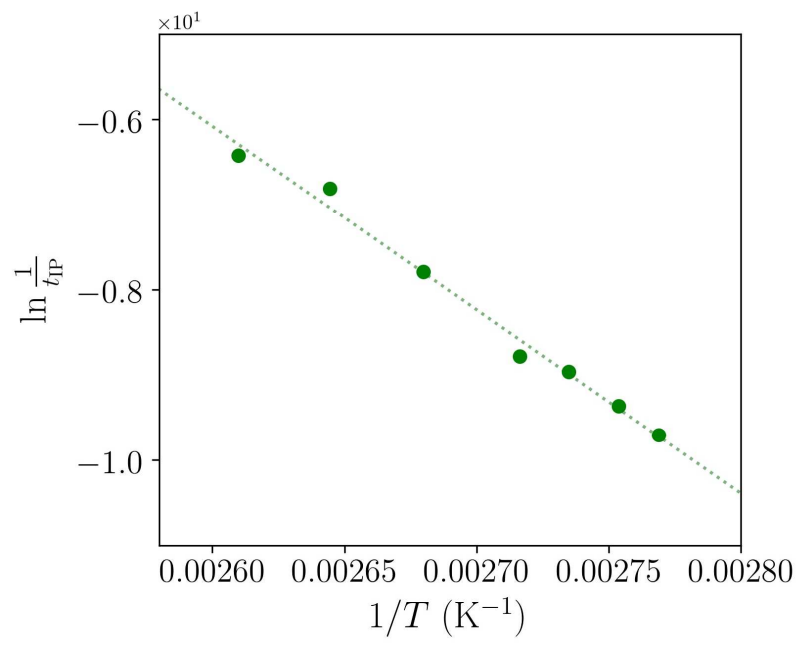

(b)

Figure 7. Evolution of the induction period with time: (a) $t_{I P}$ as a function of $T$ and (b) $1 / t_{I P}$ in Arrhenius coordinates.

\subsection{Kinetic Model Determination and Comparison with Experimental Curves}

According to the previous results and observations, we determined the following characteristics of the dehydration reaction of the $\mathrm{CaSO}_{4} \cdot 2 \mathrm{H}_{2} \mathrm{O}$ :

- The grains are dense with parallel-sided plate symmetry,

- The reaction attains the pseudo-steady state,

- " $\phi S_{\mathrm{m}}$ " test validated (up to $\alpha \approx 0.9$ ), 
- The "f $(\alpha)$ " test confirmed the case of nucleation and growth kinetic model (or two-process kinetic model required),

- Non-“instantaneous" (or slow) surface nucleation,

- Isotropic growth,

- Inward development.

Based on these characteristics of the reaction, we selected the Mampel model to fit the experimental curves and estimate the kinetic parameters. Mampel initially proposed this model for spherical particles with the same dimensions and similar behavior. ${ }^{69,70}$ Further, Delmon generalized this model for different symmetries. ${ }^{71}$ The main assumptions of this model are the presence of nuclei exhibiting inward and isotropic growth. The rate-determining step is considered to take place at the internal interface between the reactant and product within the solid. This hypothesis about the location of the rate-determining step is further discussed and verified. Soustelle et al. proposed a derivation for the Mampel model considering the kinetic parameters areic growth reactivity $\phi$ (in $\mathrm{mol} \cdot \mathrm{m}^{-2} \cdot \mathrm{s}^{-1}$ ) and areic nucleation frequency $\gamma\left(\right.$ in nuclei $\left.\cdot \mathrm{m}^{-2} \cdot \mathrm{s}^{-1}\right){ }^{16,31,39,72}$ Other authors such as Koga et al. employ another form of the Mampel model (extended Mampel's equation in the differential form) that can also take account of the surface nucleation and growth (named as a phase boundary reaction) processes separately. ${ }^{19,25,32,33,67}$

For the present study, the Mampel model development reported by Soustelle et al. was selected. This approach allows obtaining two separate parameters for nucleation and growth, $\gamma$ and $\phi$, respectively. This development also supports the consideration of geometrical characteristics of the sample, such as the symmetry of the powder particles, their dimensions, and even includes their size distributions. Finally, the geometric models and optimization calculations required for curve fitting have preliminarily been implemented in calculation routines. ${ }^{27,73-75}$ 
It is important to recall that other kinetic models commonly referred to Avrami or JMAEK models are vastly employed in the literature to model solid-gas reactions controlled simultaneously by nucleation and growth processes. These reactions are also commonly identified as complex solid-gas reactions. However, as the JMAEK models were developed for processes in which nucleation takes place in the bulk of an infinite volume sample (and not at the surface), these models are not completely appropriate to correctly describe solid-gas reactions for which surface nucleation takes place. ${ }^{24,26-28,51-53}$ More precisely, the use of such models lacks physical meaning for this category of reactions. As a consequence, there are an extensive number of kinetic studies of solid-gas reactions using JMAEK models to fit kinetic parameters from which it is unachievable to obtain meaningful physical interpretation by definition. Moreover, the kinetic parameters fitted using the JMAEK model do not allow separating the influences of nucleation and growth processes. Therefore, the use of this model does not allow to see the influences of the intensive variables (T and $\mathrm{P}_{\mathrm{H}_{2} \mathrm{O}}$ ) on both fundamental processes separately.

In this context, the Mampel model was applied to all our results systematically and the kinetic parameters for the experimental $\left(\mathrm{T}, \mathrm{P}_{\mathrm{H}_{2} \mathrm{O}}\right)$ values were estimated. These kinetic parameters were obtained using a non-linear least squares routine to minimize the differences between experimental and calculated kinetic and reaction rate curves. Figure 8 shows the comparison between experimental (complete lines) and calculated (dashed lines) curves for different $\left(\mathrm{T}, \mathrm{P}_{\mathrm{H}_{2} \mathrm{O}}\right)$ conditions. As the Mampel model does not comprise the induction periods, we have removed these branches from the curves in Figure 8a. Figure 8b shows the normalized reaction rate curves. The normalized reaction rate $\omega_{0.5}(\alpha)$ is defined by the ratio between the reaction rate values throughout the experiment and the reaction rate at $\alpha=0.5$ as expressed by the following equation 


$$
\omega_{0.5}(\alpha)=\frac{\frac{\mathrm{d} \alpha}{\mathrm{dt}}(\alpha)}{\left.\frac{\mathrm{d} \alpha}{\mathrm{dt}}\right|_{\alpha=0.5}}
$$

The choice of working with this parameter instead of the regular reaction rate is because this representation usually accentuates the difference between curves. As a consequence, this visualization allows being fairly critical concerning the applicability of the Mampel model for our experimental curves. Overall, the proposed kinetic model is adequate to express the experimental curves considering the experimental variability and the repeatability of the system. Nevertheless, the most significant model-experiment differences are present at the beginning and end of the curves. These differences can be attributed to some possible factors such as other physical phenomena that are not considered among the Mampel model hypotheses and that only influence to a reduced extent the overall dehydration process. For instance, due to an eventual change in porosity or texture, we can expect a kinetic slow-down. ${ }^{41}$ Another possibility could be that capillary condensation is taking place in one portion of the material's pores. As a consequence, liquid films can be formed within the pore network of the sample, altering the overall dehydration process kinetics to some extent. ${ }^{76,77}$ As these effects are nevertheless minor for our system due to the order of magnitude of the model-experiment differences, evaluating their contributions can be challenging and might not contribute significantly to improve our understanding of the system's chemical kinetics. 


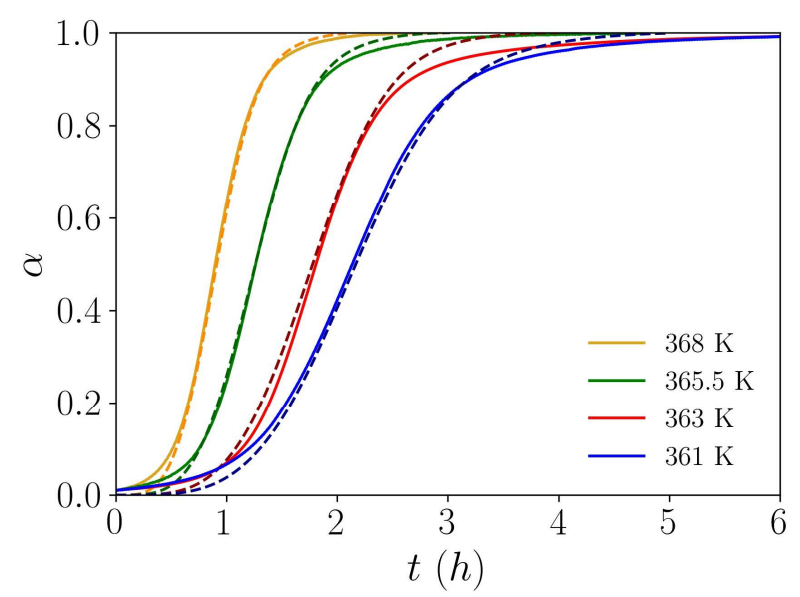

(a)

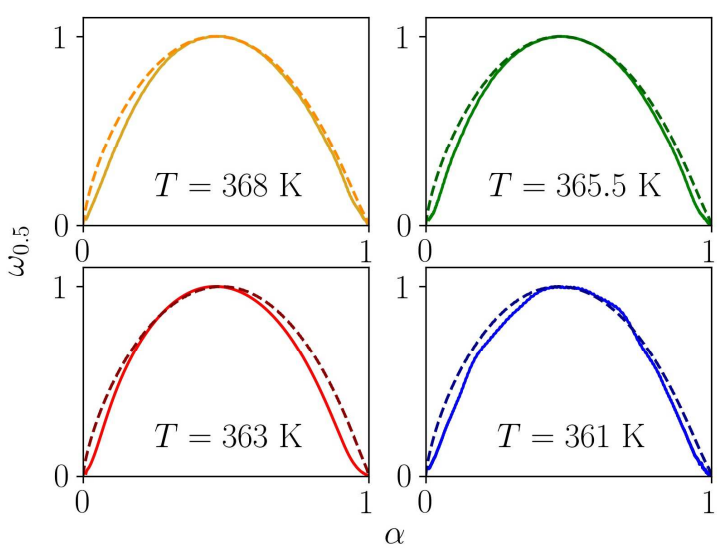

(b)

Figure 8. Model-Experiment comparison for curves obtained at constant $\mathrm{P}_{\mathrm{H}_{2} \mathrm{O}}=20 \mathrm{hPa}$ and distinct T values (temperature effect on kinetics): (a) kinetic curves and (b) normalized reaction rate curves. The fitted curves are represented in dashed lines.

Figure 9 shows similar results for experiments at the same temperature and and distinct $P_{\mathrm{H}_{2} \mathrm{O}}$ values. For both kinetic and normalized reaction rate curves, the model-experiment differences are comparable to the experimental variability of the system. These experiments reach completion more rapidly than the ones in Figure 8 due to their higher temperature. Therefore, the Mampel model is proved itself to be adapted to represent the experimental curves. 

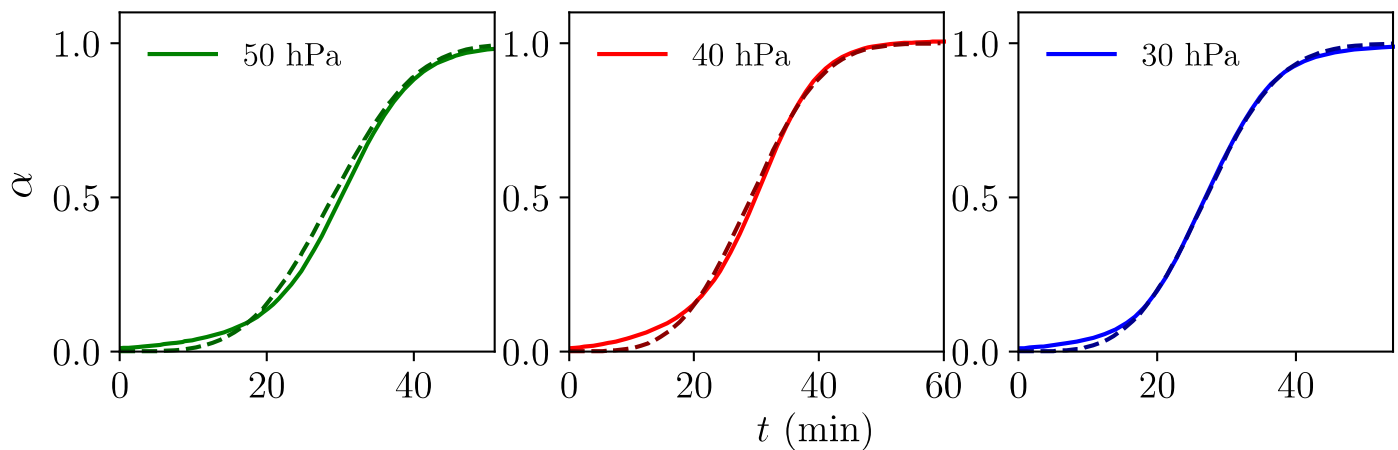

(a)
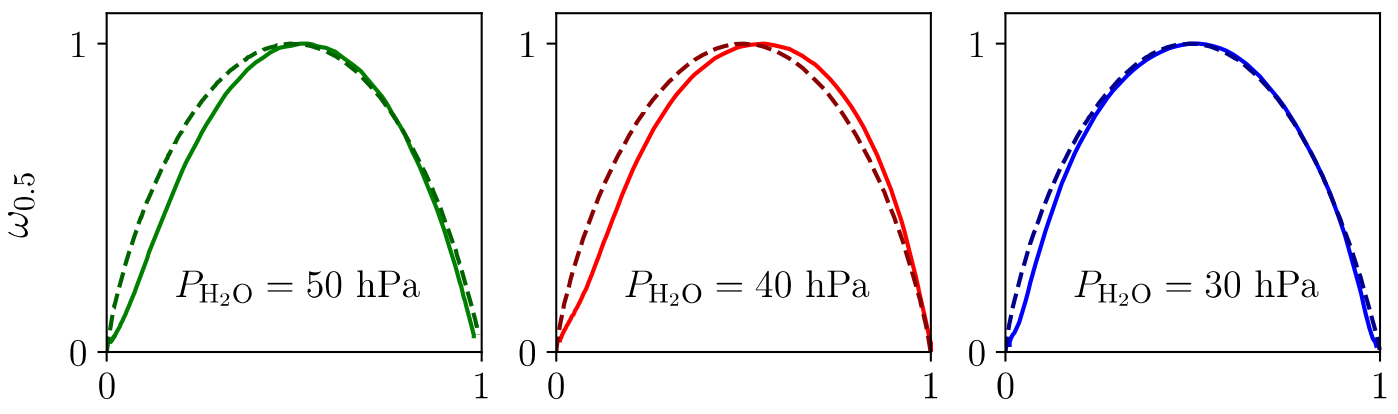

(b)

Figure 9. Model-Experiment comparison for curves obtained at $\mathrm{T}=373 \mathrm{~K}$ and distinct $\mathrm{P}_{\mathrm{H}_{2} \mathrm{O}}$ values (water vapor pressure effect on kinetics): (a) kinetic curves and (b) normalized reaction rate curves. The fitted curves are represented in dashed lines.

Figure 10 shows the plots of the fitting parameters $\phi$ and $\gamma$ obtained by applying the Mampel model to all our experimental curves. As previously observed, no effect of the water vapor partial pressure on reaction kinetics was observed for the explored experimental range. Therefore, the values of the fitting parameters were not represented as a function of $\mathrm{P}_{\mathrm{H}_{2} \mathrm{O}}$. In Figure 10a, the profile for $\phi(T)$ is exponential, which suggests an Arrhenius-type behavior. On the other hand, the profile of $\gamma(\mathrm{T})$ in Figure $10 \mathrm{~b}$ seems to show a less clear exponential profile and should be more complicated to interpret. The observed variations for a same temperature or in comparison with a plain exponential profile could be related to either the stochastic nature of the nucleation process or different temperature dependence of this parameter compared to $\phi$. These profiles are analyzed 
in more details in the following sections by considering the mechanisms of growth and surface nucleation.

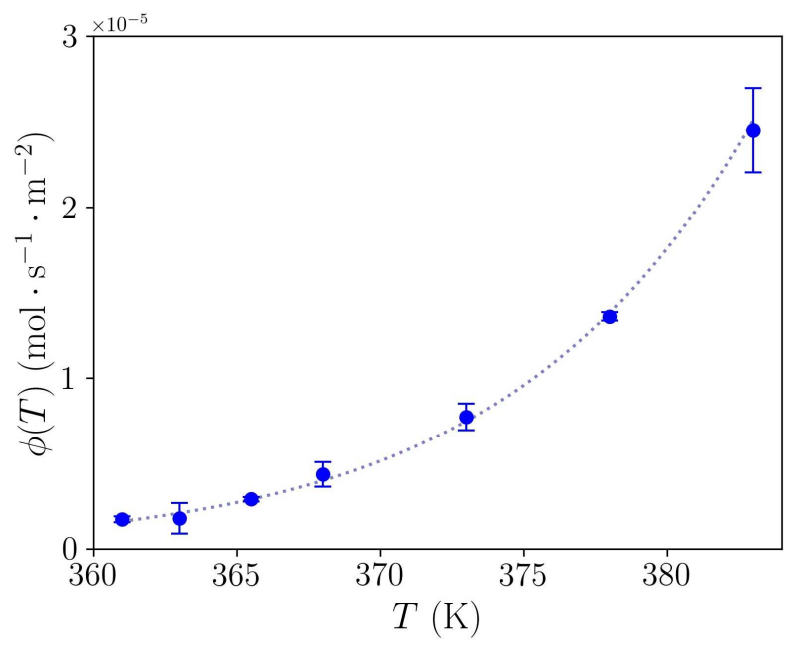

(a)

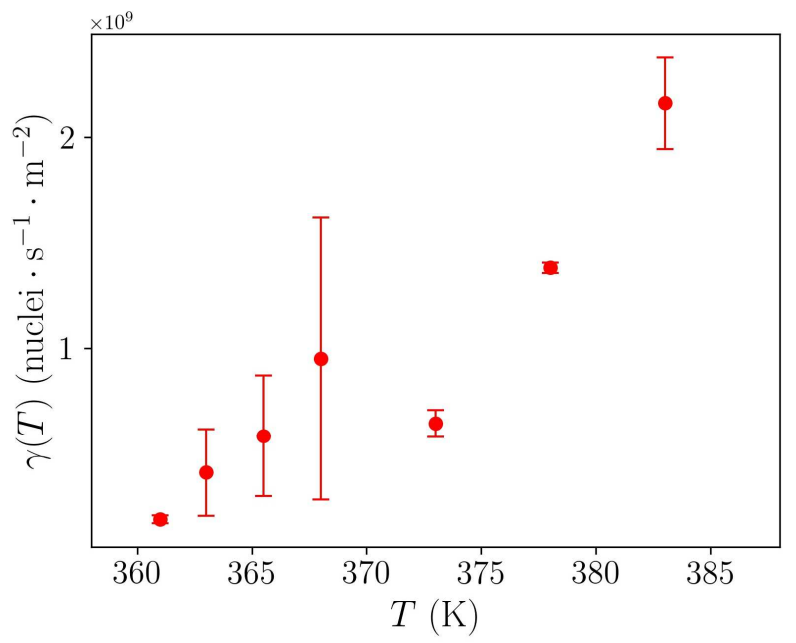

(b)

Figure 10. Plots for (a) the areic growth reactivity $\phi(T)$ and (b) the areic nucleation frequency $\gamma(T)$ with the temperature.

\subsection{Growth Process Mechanism}

A useful way to physically interpret the profile obtained for the areic growth reactivity $\phi(\mathrm{T})$ (cf. Figure 10a) is to study the mechanism for the growth process. For heterogeneous gas-solid reactions, the transformation is supposed to take place as a sequence of elementary steps that can 
be represented as quasi-equilibrium equations and using a simplified Kröger notation. ${ }^{78}$ (For the studied reaction, the species are all neutral, and we simplified their representation by omitting their electrical charges.) A scheme of this sequence of elementary steps can be observed in Figure 11. Each elementary step takes place in a given location that can be the internal interface between the reactant and product phases, the external layer of product phase, and the external interface between the product and gas phases. For the dehydration reaction of calcium sulfate dihydrate toward hemihydrate, a sequence of five elementary steps are proposed in Table 1.

The predominant point defect is assumed to be water vacancies $\mathrm{V}_{\mathrm{H}_{2} \mathrm{O}}$. Therefore, the first step consists in the creation of a water vacancy with the movement of a water molecule from a crystallographic site within the dihydrate (index DH) to an interstitial position of the hemihydrate (index $\mathrm{HH}$ ) at the internal interface. The indexes $\mathrm{H}_{2} \mathrm{O}$, i, and int represent, respectively, the crystallographic site of the water molecules, an interstitial position, and location of the species at the internal interface, respectively. The second step represents the diffusion of interstitial water in the hemihydrate from the internal toward the external interface, the latter represented by the index ext. The third step involves the migration of the interstitial water at the external surface to the adsorbed layer by the association of this water molecule with an adsorption site $\mathrm{s}$. The fourth step consists in the desorption of the adsorbed molecule generating a gaseous water molecule $\mathrm{H}_{2} \mathrm{O}_{(\mathrm{g})}$. Finally, again at the internal interface, the water vacancy undergoes annihilation with the precipitation of the product phase hemihydrate, as shown by the fifth step. This fifth and final step results in the inward development of the dehydration reaction (blue downward arrows). 


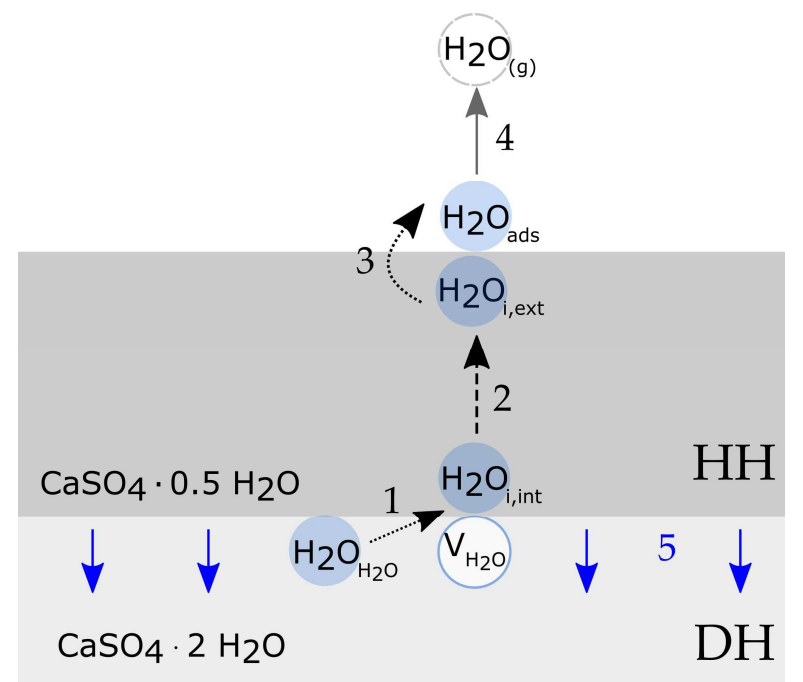

Figure 11. Scheme showing the different steps of the growth mechanism of the dehydration reaction: 1. Creation of water vacancy and interstitial water; 2 . Diffusion of interstitial water from internal interface to external interface; 3. External interface reaction; 4. Desorption of water molecule; 5. Precipitation of new solid phase with the annihilation of the water vacancy (blue arrows show the inward development direction).

The equilibrium constants $\left(\mathrm{K}_{\mathrm{i}}\right)$ for each elementary step are built from the law of mass action for each step and are shown in the third column in Table 1. Hence, we can obtain the overall equilibrium constant for the reaction in Eq. (6) by the following product

$$
\mathrm{K}_{\mathrm{eq}}=\prod_{\mathrm{i}} \mathrm{K}_{\mathrm{i}}^{\lambda_{\mathrm{i}}}=\mathrm{K}_{1}^{1.5} \mathrm{~K}_{2}^{1.5} \mathrm{~K}_{3}^{1.5} \mathrm{~K}_{4}^{1.5} \mathrm{~K}_{5}=\mathrm{P}_{\mathrm{eq}}^{1.5}(\mathrm{~T})
$$

where $\lambda_{\mathrm{i}}$ is the balance factor of the $\mathrm{i}$-th elementary step (so that the linear combination of all the elementary steps result in the overall chemical equation in Eq. (6)).

The fourth column shows the rate for each elementary step of the growth process represented by the areic growth reactivity $\phi_{\mathrm{i}}$. These parameters are represented as a function of the kinetic constants and the system's intensive variables. The first step to obtain these expressions is to consider the expression of $\phi_{\mathrm{i}}$ as given by the following rate law of the i-th elementary step considered as the rate-determining one 


$$
\phi_{\mathrm{i}}=\mathrm{k}_{\mathrm{i}} \prod_{\mathrm{i}}\left[\mathrm{X}_{\mathrm{i}}\right]^{\beta_{\mathrm{i}}}-\mathrm{k}_{\mathrm{i}}^{\prime} \prod_{\mathrm{i}}\left[\mathrm{X}_{\mathrm{i}}^{\prime}\right]^{\beta_{\mathrm{i}}^{\prime}}
$$

where:

- the term $\left[\mathrm{X}_{\mathrm{i}}\right]$ represents the activity of the reactants on the left-hand side of the $\mathrm{i}$-th elementary step,

- the term $\left[\mathrm{X}_{\mathrm{i}}^{\prime}\right]$ represents the activity of the products on the right-hand side of the $\mathrm{i}$-th elementary step,

- the terms $\beta_{\mathrm{i}}$ and $\beta_{\mathrm{i}}^{\prime}$ represent the partial orders related to species $\mathrm{X}_{\mathrm{i}}$ and $\mathrm{X}_{\mathrm{i}}^{\prime}$, respectively,

- the terms $\mathrm{k}_{\mathrm{i}}$ and $\mathrm{k}_{\mathrm{i}}^{\prime}$ represent the rate constants and follow the Arrhenius law.

Eq. (14) can preferably be re-written as follows

$$
\phi_{\mathrm{i}}=\mathrm{k}_{\mathrm{i}} \prod_{\mathrm{i}}\left[\mathrm{X}_{\mathrm{i}}\right]^{\beta_{\mathrm{i}}}\left(1-\frac{\mathrm{k}_{\mathrm{i}}^{\prime} \prod_{\mathrm{i}}\left[\mathrm{X}_{\mathrm{i}}^{\prime}\right]^{\beta_{\mathrm{i}}^{\prime}}}{\mathrm{k}_{\mathrm{i}} \prod_{\mathrm{i}}\left[\mathrm{X}_{\mathrm{i}}\right]^{\beta_{\mathrm{i}}}}\right) .
$$

This representation is useful because it puts in evidence the term $\left(1-\frac{\mathrm{k}_{\mathrm{i}}^{\prime} \prod_{\mathrm{i}}\left[\mathrm{X}_{\mathrm{i}}^{\prime}\right]_{\mathrm{i}}^{\prime}}{\mathrm{k}_{\mathrm{i}} \prod_{\mathrm{i}}\left[\mathrm{x}_{\mathrm{i}}\right]^{\beta_{\mathrm{i}}}}\right)$, which represents a shift from equilibrium conditions, and allows the replacement of the ratio $\mathrm{k}_{\mathrm{i}} / \mathrm{k}_{\mathrm{i}}^{\prime}$ by the equilibrium constant $\mathrm{K}_{\mathrm{i}}$ associated with this elementary step.

If the rate-determining step corresponds to the diffusional elementary step, i.e., step (2) in Table 1, we employ the following expression

$$
\phi_{2}=\frac{\mathrm{D} \Delta \mathrm{C}}{\ell_{0}}
$$

where $\mathrm{D}$ is the diffusion coefficient, $\Delta \mathrm{C}$ is the difference between the concentrations at the internal and external interfaces, and $\ell_{0}$ is an arbitrary length normally taken as $1 \mathrm{~m}$. 
After establishing the expressions for $\phi_{i}$, the following procedure is to develop the equilibrium constant expressions $K_{j}$ for all the other elementary steps $(i \neq j)$. In this part of the analysis, all the steps that are not rate-determining $(i \neq j)$ are considered to be in equilibrium. If the conservation of the number of adsorption sites $\mathrm{N}_{\mathrm{S}}$ is assumed, a linear system of equations is obtained and solved for each $\phi_{\mathrm{i}}$ as a function of $\left(\mathrm{T}, \mathrm{P}_{\mathrm{H}_{2} \mathrm{O}}\right)$, as shown in Table 1 .

Furthermore, for all the $\phi_{\mathrm{i}}$ expressions, there is a multiplicative term $\left[1-\left(\frac{\mathrm{P}_{\mathrm{H}_{2} \mathrm{O}}}{\mathrm{P}_{\mathrm{eq}}(\mathrm{T})}\right)^{\mathrm{m}}\right]$, where $\mathrm{m}=1$ or $\mathrm{m}=1.5$. This term represents the distance between experimental and equilibrium conditions and is customarily referred to as the conventional accommodation function as recalled by Eq. (4) when $m=1$. To evaluate the importance of this term for our experimental range, we traced its numerical values for $m=1$ in Figure 12a. The shift from equilibrium function is close to 1 for the whole of our experimental $\left(\mathrm{T}, \mathrm{P}_{\mathrm{H}_{2} \mathrm{O}}\right)$ range, which is expected because our experimental conditions are considerably far from the equilibrium curve, i.e., $\mathrm{P}_{\mathrm{eq}}(\mathrm{T}) \gg \mathrm{P}_{\mathrm{H}_{2} \mathrm{O}}$ for our investigated T interval. 
Table 1. Growth mechanism elementary steps.

\begin{tabular}{|c|c|c|c|}
\hline Elementary step $i$ & Chemical reaction & Equilibrium constant $K_{i}$ & Areic growth reactivity $\phi_{i}$ \\
\hline $\begin{array}{l}\text { (1) Creation of water } \\
\text { vacancy with the } \\
\text { migration of structural } \\
\text { water to interstitial } \\
\text { position at the internal } \\
\text { interface }\end{array}$ & $\left(\mathrm{H}_{2} \mathrm{O}_{\mathrm{H}_{2} \mathrm{O}}\right)_{\mathrm{DH}} \rightleftharpoons\left(\mathrm{V}_{\mathrm{H}_{2} \mathrm{O}}\right)_{\mathrm{DH}}+\left(\mathrm{H}_{2} \mathrm{O}_{\mathrm{i}, \mathrm{int}}\right)_{\mathrm{HH}}$ & $\mathrm{K}_{1}=\left[\left(\mathrm{V}_{\mathrm{H}_{2} \mathrm{O}}\right)_{\mathrm{DH}}\right]\left[\left(\mathrm{H}_{2} \mathrm{O}_{\mathrm{i}, \text { int }}\right)_{\mathrm{HH}}\right]$ & $\phi_{1}=\mathrm{k}_{1}\left(1-\frac{\mathrm{P}_{\mathrm{H}_{2} \mathrm{O}}}{\mathrm{P}_{\mathrm{eq}}(\mathrm{T})}\right)$ \\
\hline $\begin{array}{l}\text { (2) Diffusion of interstitial } \\
\text { water from the internal to } \\
\text { the external interface }\end{array}$ & $\left(\mathrm{H}_{2} \mathrm{O}_{\mathrm{i}, \mathrm{int}}\right)_{\mathrm{HH}} \rightleftharpoons\left(\mathrm{H}_{2} \mathrm{O}_{\mathrm{i}, \mathrm{ext}}\right)_{\mathrm{HH}}$ & $\mathrm{K}_{2}=\frac{\left\lfloor\left(\mathrm{H}_{2} \mathrm{O}_{\mathrm{i}, \mathrm{ext}}\right)_{\mathrm{HH}}\right]}{\left[\left(\mathrm{H}_{2} \mathrm{O}_{\mathrm{i}, \mathrm{int}}\right)_{\mathrm{HH}}\right]}=1$ & $\phi_{2}=\frac{\mathrm{DK}_{1} \mathrm{~K}_{5}^{2 / 3}}{\mathrm{l}_{0}}\left(1-\frac{\mathrm{P}_{\mathrm{H}_{2} \mathrm{O}}}{\mathrm{P}_{\mathrm{eq}}(\mathrm{T})}\right)$ \\
\hline $\begin{array}{l}\text { (3) External interface } \\
\text { reaction, water molecule } \\
\text { moves to the adsorbed } \\
\text { layer }\end{array}$ & $\left(\mathrm{H}_{2} \mathrm{O}_{\mathrm{i}, \mathrm{ext}}\right)_{\mathrm{HH}}+\mathrm{s} \rightleftharpoons \mathrm{H}_{2} \mathrm{O}_{\mathrm{ads}} \mathrm{S}$ & $\mathrm{K}_{3}=\frac{\left[\mathrm{H}_{2} \mathrm{O}_{\mathrm{ads}} \mathrm{s}\right]}{\left[\left(\mathrm{H}_{2} \mathrm{O}_{\mathrm{i}, \mathrm{ext}}\right)_{\mathrm{HH}}\right][\mathrm{s}]}$ & $\phi_{3}=\frac{\mathrm{k}_{3} \mathrm{~N}_{\mathrm{s}} \mathrm{K}_{1} \mathrm{~K}_{4} \mathrm{~K}_{5}^{2 / 3}}{\mathrm{~K}_{4}+\mathrm{P}_{\mathrm{H}_{2} \mathrm{O}}}\left(1-\frac{\mathrm{P}_{\mathrm{H}_{2} \mathrm{O}}}{\mathrm{P}_{\mathrm{eq}}(\mathrm{T})}\right)$ \\
\hline $\begin{array}{l}\text { (4) Desorption from the } \\
\text { adsorbed layer to the } \\
\text { surrounding } \\
\text { medium }\end{array}$ & $\mathrm{H}_{2} \mathrm{O}_{\mathrm{ads}} \mathrm{S} \rightleftharpoons \mathrm{H}_{2} \mathrm{O}_{(\mathrm{g})}+\mathrm{s}$ & $\mathrm{K}_{4}=\frac{\mathrm{P}_{\mathrm{H}_{2} \mathrm{O}}[\mathrm{s}]}{\left[\mathrm{H}_{2} \mathrm{O}_{\mathrm{ads}} \mathrm{s}\right]}$ & $\phi_{4}=\frac{\mathrm{k}_{4} \mathrm{~N}_{\mathrm{s}} \mathrm{K}_{1} \mathrm{~K}_{3} \mathrm{~K}_{5}^{2 / 3}}{1+\mathrm{K}_{1} \mathrm{~K}_{3} \mathrm{~K}_{5}^{2 / 3}}\left(1-\frac{\mathrm{P}_{\mathrm{H}_{2} \mathrm{O}}}{\mathrm{P}_{\mathrm{eq}}(\mathrm{T})}\right)$ \\
\hline $\begin{array}{l}\text { (5) Annihilation of the } \\
\text { water vacancy with } \\
\text { precipitation of the phase } \\
\text { HH and inward growth }\end{array}$ & $\begin{aligned}\left(\mathrm{CaSO}_{4 \mathrm{CasO}_{4}}+\right. & \left.0.5 \mathrm{H}_{2} \mathrm{O}_{\mathrm{H}_{2} \mathrm{O}}+1.5 \mathrm{~V}_{\mathrm{H}_{2} \mathrm{O}}\right)_{\mathrm{DH}} \\
& \rightleftharpoons\left(\mathrm{CaSO}_{4} \mathrm{CasO}_{4}+0.5 \mathrm{H}_{2} \mathrm{O}_{\mathrm{H}_{2} \mathrm{O}}\right)_{\mathrm{HH}}\end{aligned}$ & $\mathrm{K}_{5}=\frac{1}{\left[\left(\mathrm{~V}_{\mathrm{H}_{2} \mathrm{O}}\right)_{\mathrm{DH}}\right]^{1.5}}$ & $\phi_{5}=\frac{\mathrm{k}_{5} \mathrm{~K}_{1}^{1.5} \mathrm{~K}_{3}^{1.5} \mathrm{~K}_{4}^{1.5}}{\mathrm{P}_{\mathrm{H}_{2} \mathrm{O}}^{1.5}}\left[1-\left(\frac{\mathrm{P}_{\mathrm{H}_{2} \mathrm{O}}}{\mathrm{P}_{\mathrm{eq}}(\mathrm{T})}\right)^{1.5}\right.$ \\
\hline
\end{tabular}


The final part of this analysis is to compare the areic growth reactivity expressions for the different elementary steps with the objective of determining the rate-determining step. According to the proposed kinetics model, the location of the rate-determining step is at the internal interface. Therefore, the only possible elementary steps that control the reaction rate are the first and the fifth step as they are the only ones taking place at the internal interface. After that, the effect of $\mathrm{P}_{\mathrm{H}_{2} \mathrm{O}}$ on the reaction rate was shown to be negligible for the investigated experimental range. As a consequence, its effect on the $\phi(\mathrm{T})$ values is also negligible. Therefore, as the shift from equilibrium term $\left[1-\left(\frac{\mathrm{P}_{\mathrm{H}_{2} \mathrm{O}}}{\mathrm{P}_{\mathrm{eq}}(\mathrm{T})}\right)^{\mathrm{m}}\right]$ was shown not to be representative in the investigated experimental range, the consideration of the term preceding this function in the expressions of $\phi_{1}$ and $\phi_{5}$ is necessary. For $\phi_{5}$, this preceding term is a function of $\mathrm{P}_{\mathrm{H}_{2} \mathrm{O}}^{-1.5}$, whereas no $\mathrm{P}_{\mathrm{H}_{2} \mathrm{O}}$ dependence appears for $\phi_{1}$ with the exception of the shift from equilibrium term. Hence, according to these criteria, the rate-determining step should be the first elementary step, in which the structural water molecules move from the calcium sulfate dihydrate structure toward interstitial positions in the hemihydrate.

The expression of $\phi_{1}$ was then compared with the fitted values of $\phi(T)$ in Figure 10a to estimate the values of the kinetic parameters. Even though the contribution of the shift from equilibrium has been proved to be close to the unit value, $\phi(\mathrm{T})$ was still devided by it to produce the most accurate kinetic constants values as possible. Therefore, the following expression was plotted in Arrhenius coordinates

$$
\frac{\phi(\mathrm{T})}{\left(1-\frac{\mathrm{P}_{\mathrm{H}_{2} \mathrm{O}}}{\mathrm{P}_{\mathrm{e}}(\mathrm{T})}\right)}=\mathrm{k}_{1}=\mathrm{k}_{0,1} \exp \left(-\frac{\mathrm{E}_{\mathrm{a}, 1}}{\mathrm{RT}}\right)
$$

where $\mathrm{k}_{1}$ follows the Arrhenius law, $\mathrm{k}_{0,1}$ is the pre-exponential factor, and $\mathrm{E}_{\mathrm{a}, 1}$ is the activation energy value for the first elementary step. For this specific reaction, it is possible to obtain the actual value of the activation energy of the rate-determining step and not an apparent activation 
energy value combined with other energetic terms. Figure $12 \mathrm{~b}$ shows the Arrhenius plot for these points. The kinetic parameters obtained from the linear regression were $\ln \mathrm{k}_{0,1}=34.7$ and $E_{a, 1}=144 \mathrm{~kJ} \cdot \mathrm{mol}^{-1}$. Finally, it is essential to recall that from rigorous mechanistic assumptions, some important aspects concerning the physical chemistry of the system were confirmed. The kinetic parameter $\phi$ corresponding to the rate-determining step follows the Arrhenius law, and the influence of the water vapor pressure on reaction kinetic depends only on the shift from equilibrium (which in the present case can be considered as the previously mentioned accommodation function) if the rate-determining step remains unchanged.

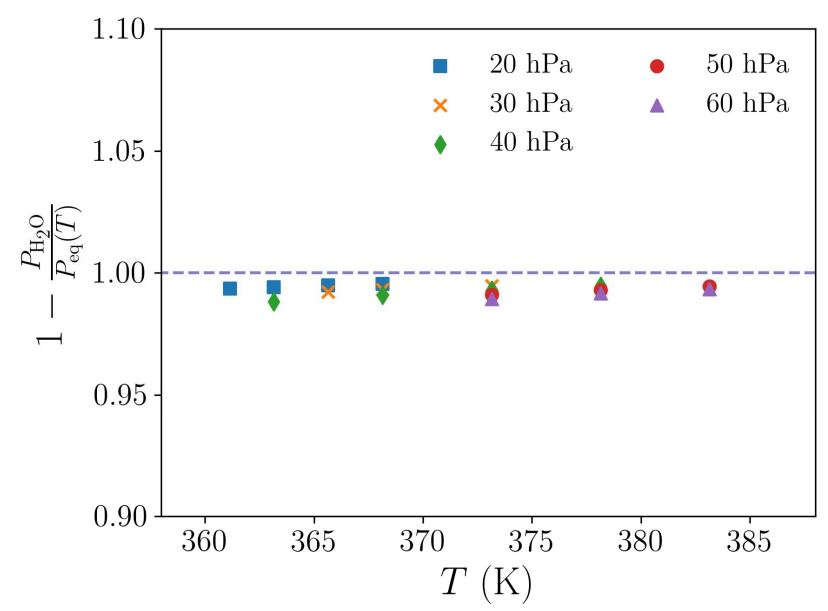

(a)

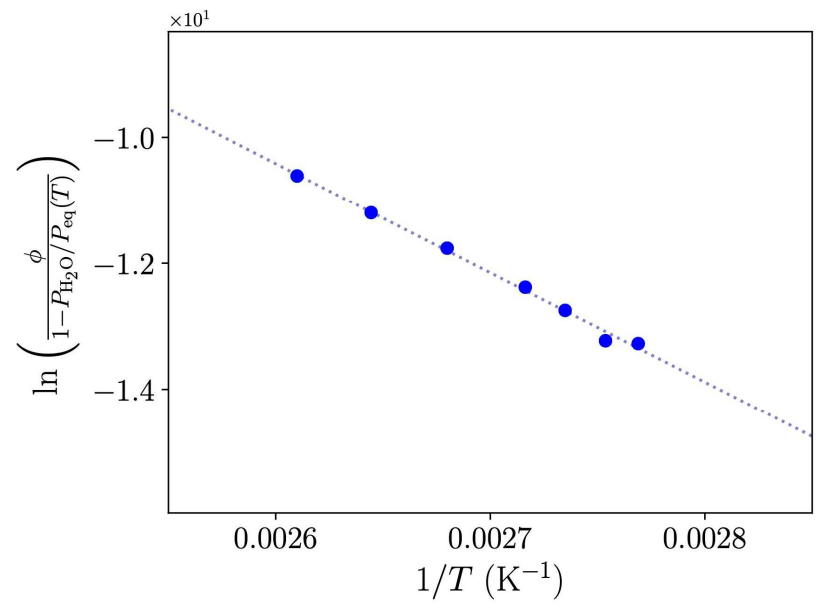

(b)

Figure 12. (a) Equilibrium shift term and (b) Arrhenius plot for the surface growth reactivity divided by the shift from equilibrium conditions $\phi /\left(1-\mathrm{P}_{\mathrm{H}_{2} \mathrm{O}} / \mathrm{P}_{\mathrm{e}}(\mathrm{T})\right)\left(\mathrm{R}^{2}=0.9936\right)$. 


\subsection{Nucleation Process Mechanism}

After analyzing the evolution of $\phi(\mathrm{T})$, a mechanism for the nucleation process was developed in order to propose physical interpretation for the evolution of $\gamma(\mathrm{T})$. Unlike the growth process that corresponds to the progression of the interface between both solid phases, the nucleation process corresponds to the establishment of this interface. Nucleation mechanisms are usually more complicated to determine because they require in-depth knowledge about the surface properties of the sample, and these are not straightforward to verify. ${ }^{79}$ For instance, the determination of the number of point defects necessary for the precipitation of the product phase is not a feasible experimental procedure to our knowledge. Nevertheless, a generalized interpretation based on a similar approach to the analysis of the growth process can be structured. ${ }^{18,32,33}$ Hence, for heterogeneous solid-gas reactions, the nucleation process is also supposed to take place as a sequence of elementary steps. These steps are usually represented as quasi-equilibrium equations that can be written using the Kröger notation similarly to the previously proposed mechanism. Table 2 shows three proposed elementary steps, their equilibrium constants, and their rates when they are considered to be rate-determining.

Similarly to the previously shown mechanism, the predominant point defect is also assumed to be water vacancies $\mathrm{V}_{\mathrm{H}_{2} \mathrm{O}}$. Therefore, the first step consists in the creation of a water vacancy with the movement of a water molecule from a crystallographic site within the dihydrate to an adsorbed site. The second step consists in the desorption of the adsorbed molecule generating a gaseous water molecule $\mathrm{H}_{2} \mathrm{O}_{(\mathrm{g})}$. Finally, in the third step, we generate the internal and external interfaces when a number $n$ of point defects associate with the annihilation of water vacancies and the precipitation of the product phase, i.e. the hemihydrate.

The equilibrium constants were determined from the law of mass action, and their association produces the overall equilibrium constant for the nucleation process as follows

$$
\mathcal{K}=\prod_{\mathrm{i}} \mathcal{K}_{1}^{\mathrm{n}} \mathcal{K}_{2}^{\mathrm{n}} \mathcal{K}_{3}=\mathrm{P}_{\mathrm{eq}}^{\mathrm{n}}
$$


For this analysis, the equilibrium pressure for the nucleation process is considered to be equal to the equilibrium pressure for the overall dehydration reaction. The rates for each nucleation elementary step $\gamma_{\mathrm{i}}$ were developed as a function of a kinetic parameter $\kappa_{\mathrm{i}}$ following the Arrhenius law, the equilibrium constants for the nucleation elementary steps, the intensive variables of the system, and a $\mathrm{P}_{\mathrm{H}_{2} \mathrm{O}}$ dependent function expressing the distance or shift from equilibrium conditions.

The shift from equilibrium functions follow the same behavior as previously stated as they show values considerably close to 1 for the investigated experimental range. Therefore, the multiplicative term preceding this term should be linked to the profile obtained for the fitted values of $\gamma(\mathrm{T})$ in Figure 10b. As no effect of $\mathrm{P}_{\mathrm{H}_{2} \mathrm{O}}$ is observed on the reaction kinetics for the investigated experimental range, we select the second step as the rate-determining for the nucleation process because it is the only one that does not contain pressure dependence outside of the shift from equilibrium function. Hence, to analyze the profile of $\gamma(\mathrm{T})$, the following expression is considered

$$
\frac{\gamma(\mathrm{T})}{\left(1-\frac{\mathrm{P}_{\mathrm{H}_{2} \mathrm{O}}}{\mathrm{P}_{\mathrm{eq}}(\mathrm{T})}\right)}=\frac{\kappa_{2} \mathcal{K}_{1} \mathcal{K}_{3}^{\frac{1}{1.5 \mathrm{n}}}}{1+\mathcal{K}_{1} \mathcal{K}_{3}^{\frac{1}{1.5 \mathrm{n}}}}
$$

where the following definitions for the Arrhenius kinetic constant $\kappa_{2}$ and for the equilibrium constants $\mathcal{K}_{\mathrm{i}}$ are

$$
\kappa_{2}=\kappa_{2,0} \exp \left(-\frac{\Xi_{2}}{\mathrm{RT}}\right)
$$

(20)

$$
\mathcal{K}_{\mathrm{i}}=\exp \left(\frac{\Delta_{\text {nucl, } \mathrm{i}} \mathrm{S}}{\mathrm{RT}}\right) \approx \mathcal{K}_{\mathrm{i}, 0} \exp \left(-\frac{\Delta_{\text {nucl, } \mathrm{i}} \mathrm{H}}{\mathrm{RT}}\right)
$$


where $\Xi_{2}$ is the activation energy of the second elementary step and $\Delta_{\text {nucl,i }} \mathrm{S}$ and $\Delta_{\text {nucl,i }} \mathrm{H}$ are the changes in entropy and enthalpy for the elementary steps of the nucleation mechanism.

Usually, to reduce Eq. (19), the term $\mathrm{K}_{1} \mathrm{~K}_{3}^{\frac{1}{1.5 n}}$ is either much larger or smaller than unity. For the former, the expression simplifies to an Arrhenius law equation as follows

$$
\frac{\gamma(\mathrm{T})}{\left(1-\frac{\mathrm{P}_{\mathrm{H}_{2} \mathrm{O}}}{\mathrm{P}_{\mathrm{eq}}(\mathrm{T})}\right)}=\kappa_{2}=\kappa_{2,0} \exp \left(-\frac{\Xi_{2}}{\mathrm{RT}}\right) \text {. }
$$

For the latter, we obtain the following expression for which the temperature dependence of the left-hand side term is more complicated as follows

$$
\frac{\gamma(\mathrm{T})}{\left(1-\frac{\mathrm{P}_{\mathrm{H}_{2} \mathrm{O}}}{\mathrm{P}_{\mathrm{eq}}(\mathrm{T})}\right)}=\kappa_{2} \mathcal{K}_{1} \mathcal{K}_{3}^{\frac{1}{1.5 \mathrm{n}}}=\kappa_{2,0} \mathcal{K}_{0,1} \mathcal{K}_{0,3}^{\frac{1}{1.5 \mathrm{n}}} \exp \left[-\frac{1}{\mathrm{RT}}\left(\Xi_{2}+\Delta_{\mathrm{nucl}, 1} \mathrm{H}^{\circ}+1.5 \mathrm{n} \Delta_{\mathrm{nucl}, 3} \mathrm{H}^{\circ}\right)\right]
$$

which can also be rearranged as an Arrhenius-law type equation with apparent pre-exponential factor $\kappa_{\mathrm{app}}$ and activation energy $\mathrm{E}_{\mathrm{app}}$ as follows:

$$
\frac{\gamma(\mathrm{T})}{\left(1-\frac{\mathrm{P}_{\mathrm{H}_{2} \mathrm{O}}}{\mathrm{P}_{\mathrm{eq}}(\mathrm{T})}\right)}=\kappa_{\mathrm{app}} \exp \left(-\frac{\mathrm{E}_{\mathrm{app}}}{\mathrm{RT}}\right)
$$

Both simplifications lead to Arrhenius-type equations. We can then propose the Arrhenius plot in Figure 13, which shows the fitted values of $\gamma(\mathrm{T})$ using the Mampel kinetic model divided by the accommodation function. From this plot, the kinetic constants obtained by a linear regression method are $\ln \kappa_{2,0}=58.5\left(\right.$ or $\left.\ln \kappa_{\mathrm{app}}\right)$ and $\Xi_{2}=118 \mathrm{~kJ} \cdot \mathrm{mol}^{-1}\left(\right.$ or $\left.\mathrm{E}_{\mathrm{app}}\right)$.

Finally, the last thing to evaluate is whether the simplification cases are pertinent for this system and, if yes, which case is adequate. As both simplifications lead to an Arrhenius-type equation, it is not possible to directly use the expressions and the profile to evaluate which case is adapted 
for the system. Therefore, it is necessary to consider the complete expression represented as follows

$$
\frac{\gamma(\mathrm{T})}{\left(1-\frac{\mathrm{P}_{\mathrm{H}_{2} \mathrm{O}}}{\mathrm{P}_{\mathrm{eq}}(\mathrm{T})}\right)}=\frac{\kappa_{2,0} \mathcal{K}_{0,1} \mathcal{K}_{0,3}^{\frac{1}{1.5 \mathrm{n}}} \exp \left[-\frac{1}{\mathrm{RT}}\left(\Xi_{2}+\Delta_{\mathrm{nucl}, 1} \mathrm{H}^{\circ}+1.5 \mathrm{n} \Delta_{\mathrm{nucl}, 3} \mathrm{H}^{\circ}\right)\right]}{1+\mathcal{K}_{0,1} \mathcal{K}_{0,3}^{\frac{1}{1.5 \mathrm{n}}} \exp \left[-\frac{1}{\mathrm{RT}}\left(\Delta_{\mathrm{nucl}, 1} \mathrm{H}^{\circ}+1.5 \mathrm{n} \Delta_{\mathrm{nucl}, 3} \mathrm{H}^{\circ}\right)\right]}
$$

Some of these parameters can then be fitted by a non-linear least-squares optimization calculation. For this, the minimization of the objective function is necessary. This function represent the residues between the experimental results and the calculated results obtained from this function. The imposed constraint was the activation energy $\Xi_{2}$ needs to be positive by definition. The only possible optimization results obtained with this constraint are shown in Table 3. These values confirm that the simplifications are pertinent for this case due to the proximity of the fitted parameters. They also allow verifying that the first case, for which $\mathrm{K}_{1} \mathrm{~K}_{3}^{\frac{1}{1.5 \mathrm{n}}} \gg 1$, is the most adapted for the system. 
Table 2. Nucleation mechanism elementary steps.

\begin{tabular}{|c|c|c|c|}
\hline Elementary step $i$ & Chemical reaction & Equilibrium constant $\mathcal{K}_{i}$ & Areic growth reactivity $\gamma_{i}$ \\
\hline $\begin{array}{l}\text { (1) Creation of water } \\
\text { vacancy with the } \\
\text { migration of structural } \\
\text { water to an adsorbed site }\end{array}$ & $\left(\mathrm{H}_{2} \mathrm{O}_{\mathrm{H}_{2} \mathrm{O}}\right)_{\mathrm{DH}}+\mathrm{s} \rightleftharpoons\left(\mathrm{V}_{\mathrm{H}_{2} \mathrm{O}}\right)_{\mathrm{DH}}+\mathrm{H}_{2} \mathrm{O}_{\mathrm{ads}} \mathrm{s}$ & $\mathcal{K}_{1}=\frac{\left[\left(\mathrm{V}_{\mathrm{H}_{2} \mathrm{O}}\right)_{\mathrm{DH}}\right]\left[\mathrm{H}_{2} \mathrm{O}_{\mathrm{ads}} \mathrm{s}\right]}{[\mathrm{s}]}$ & $\gamma_{1}=\frac{\kappa_{1} K_{2}}{K_{2}+P_{\mathrm{H}_{2} \mathrm{O}}}\left(1-\frac{\mathrm{P}_{\mathrm{H}_{2} \mathrm{O}}}{\mathrm{P}_{\mathrm{eq}}(\mathrm{T})}\right)$ \\
\hline $\begin{array}{l}\text { (2) Desorption from the } \\
\text { adsorbed layer to the } \\
\text { surrounding } \\
\text { medium }\end{array}$ & $\mathrm{H}_{2} \mathrm{O}_{\mathrm{ads}} \mathrm{S} \rightleftharpoons \mathrm{H}_{2} \mathrm{O}_{(\mathrm{g})}+\mathrm{s}$ & $\mathcal{K}_{2}=\frac{\mathrm{P}_{\mathrm{H}_{2} \mathrm{O}}[\mathrm{s}]}{\left[\mathrm{H}_{2} \mathrm{O}_{\mathrm{ads}} \mathrm{s}\right]}$ & $\gamma_{2}=\frac{\kappa_{2} K_{1} K_{3}^{\frac{1}{1.5 n}}}{1+K_{1} K_{3}^{\frac{1}{1.5 n}}}\left(1-\frac{\mathrm{P}_{\mathrm{H}_{2} \mathrm{O}}}{\mathrm{P}_{\mathrm{eq}}(\mathrm{T})}\right)$ \\
\hline $\begin{array}{l}\text { (3) Annihilation of the } \\
\text { water vacancy with } \\
\text { precipitation of the phase } \\
\text { HH and inward growth }\end{array}$ & $\begin{aligned}\left(\mathrm{nCaSO}_{4 \mathrm{CasO}_{4}}+\right. & \left.0.5 \mathrm{nH}_{2} \mathrm{O}_{\mathrm{H}_{2} \mathrm{O}}+1.5 \mathrm{nV}_{\mathrm{H}_{2} \mathrm{O}}\right)_{\mathrm{DH}} \\
& \rightleftharpoons\left(\mathrm{nCaSO}_{4} \mathrm{CasO}_{4}+0.5 \mathrm{nH}_{2} \mathrm{O}_{\mathrm{H}_{2} \mathrm{O}}\right)_{\mathrm{HH}}\end{aligned}$ & $\mathcal{K}_{3}=\frac{1}{\left[\left(\mathrm{~V}_{\mathrm{H}_{2} \mathrm{O}}\right)_{\mathrm{DH}}\right]^{1.5 \mathrm{n}}}$ & $\gamma_{3}=\frac{\kappa_{3} \mathrm{~K}_{1}^{1.5 n} \mathrm{~K}_{2}^{1.5 n}}{\mathrm{P}_{\mathrm{H}_{2} \mathrm{O}}^{1.5 \mathrm{n}}}\left[1-\left(\frac{\mathrm{P}_{\mathrm{H}_{2} \mathrm{O}}}{\mathrm{P}_{\mathrm{eq}}(\mathrm{T})}\right)^{1.5 \mathrm{n}}\right]$ \\
\hline
\end{tabular}




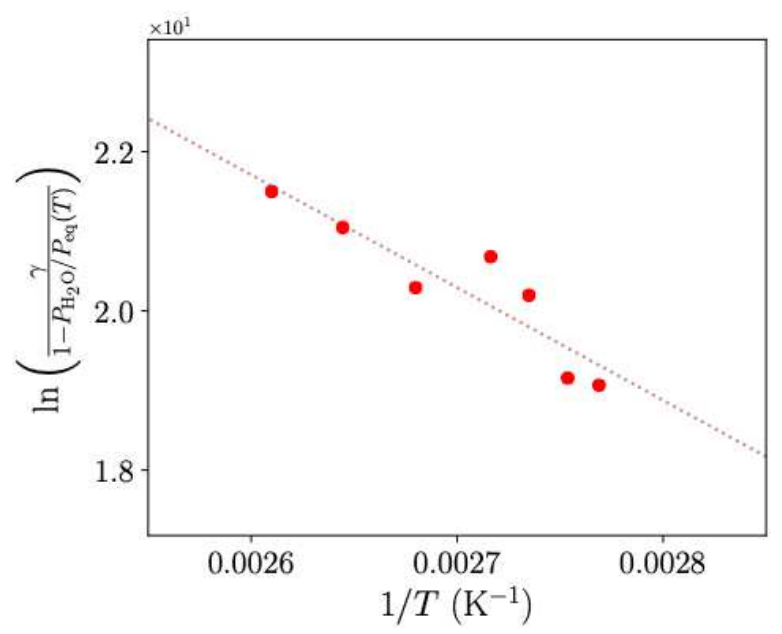

Figure 13. Arrhenius plot of the $\gamma /\left(1-\mathrm{P}_{\mathrm{H}_{2} \mathrm{O}} / \mathrm{P}_{\mathrm{e}}(\mathrm{T})\right)$ with the linear regression dotted line $\left(\mathrm{R}^{2}=\right.$ $0.8332)$.

Table 3. Fitted Parameters for nucleation from Eq. (25).

\begin{tabular}{cccc}
\hline $\ln \kappa_{2,0}$ & $\Xi_{2}\left(\mathrm{~kJ} \cdot \mathrm{mol}^{-1}\right)$ & $\mathcal{K}_{0,1} \mathcal{K}_{0,3}^{\frac{1}{1.5 n}}$ & $\Delta_{\text {nucl, } 1} \mathrm{H}^{\circ}+1.5 \mathrm{n} \Delta_{\mathrm{nucl}, 3} \mathrm{H}^{\circ}\left(\mathrm{kJ} \cdot \mathrm{mol}^{-1}\right)$ \\
\hline 75.48 & 119.1 & $1.374 \cdot 10^{6}$ & 7.832 \\
\hline
\end{tabular}

\section{CONCLUSIONS}

We studied the kinetic aspects of the $\mathrm{CaSO}_{4} \cdot 2 \mathrm{H}_{2} \mathrm{O}$ dehydration reaction to form $\mathrm{CaSO}_{4}$. $0.5 \mathrm{H}_{2} \mathrm{O}$ in isothermal and isobaric conditions using a synthetic powder with high purity and natural gypsum samples. The reaction was observed to take place initially by a nucleation step with formation of isotropic growth domains at the surface of the sample. Finally, the samples particles are completely filled with cracks by the end of the reaction.

Afterward, the development of a kinetic model based on the observed experimental results considering the physical nature of the investigated transformation was presented. The Mampel model was retained from the literature and was employed to represent the kinetic and reaction rate curves by considering the plate-like geometry of the particles. To refine the kinetic model, the effect of particle size distribution was incorporated in the calculations. This model 
was capable of representing the experimental curves taking into account the experimental variability for this system.

The fitted kinetic parameters areic growth reactivity $\phi$ and areic nucleation frequency $\gamma$ were then obtained as a function of the temperature. Growth and nucleation mechanisms were proposed to provide a physicochemical interpretation for both profiles. For the growth mechanism, the mechanism of dehydration contains five elementary steps. By analyzing the analytical expressions of $\phi$ in comparison with the fitted data, the rate-determining step was determined along with its location at the internal interface between phases $\mathrm{CaSO}_{4} \cdot 2 \mathrm{H}_{2} \mathrm{O}$ and $\mathrm{CaSO}_{4} \cdot 0.5 \mathrm{H}_{2} \mathrm{O}$. This part of the analysis also allowed the estimation of the activation energy value for the reaction as $144 \mathrm{~kJ} \cdot \mathrm{mol}^{-1}$ and the logarithm of the pre-exponential factor as 34.7 . The nucleation mechanism contained three elementary steps and was somewhat more challenging to analyze due to the stochastic nature of this fundamental process. We could retain a desorption rate-determining step for this process, but other experiments would be necessary to better describe it at an atomic scale.

Other interesting observations can be highlighted about this system. The results in the experimental section confirmed the presence of a nucleation-growth competition taking place throughout the reaction. Afterward, the isotropic nature of the growth process was confirmed for this reaction by employing different experimental techniques and samples. Then, a kinetic model that is built upon these assumptions was applied (Mampel model). Moreover, this modeling procedure allowed not only taking the system's intensive variables into account, but also the morphological and geometrical properties of our sample. Finally, the mechanistic view of the reaction was proposed as well as rate-determining steps for both fundamental processes. Finally, the set of the used methods can also be considered as a comprehensive or universal approach for studying the thermal decomposition of other ionic hydrates. 


\section{ACKNOWLEDGMENTS}

The authors would like to thank Saint-Gobain for funding this work.

\section{SUPPORTING INFORMATION}

Additional experimental results and precisions are available free of charge on the ACS Publication website. 


\section{REFERENCES}

(1) Nonnet, E.; Lequeux, N.; Boch, P. Elastic Properties of High Alumina Cement Castables from Room Temperature to $1600^{\circ}$ C. J. Eur. Ceram. Soc. 1999, 19 (8), 1575-1583.

(2) Alarcon-Ruiz, L.; Platret, G.; Massieu, E.; Ehrlacher, A. The Use of Thermal Analysis in Assessing the Effect of Temperature on a Cement Paste. Cem. Concr. Res. 2005, 35 (3), 609-613.

(3) Zhou, Q.; Glasser, F. P. Thermal Stability and Decomposition Mechanisms of Ettringite at $<120^{\circ}$ C. Cem. Concr. Res. 2001, 31 (9), 1333-1339.

(4) Kuntze, R. A. Gypsum: Connecting Science and Technology, 1st ed.; ASTM International: PA, USA, 2009.

(5) Preturlan, J. G. D.; Vieille, L.; Quiligotti, S.; Favergeon, L. Comprehensive Thermodynamic Study of the Calcium Sulfate-Water Vapor System. Part 1: Experimental Measurements and Phase Equilibria. Ind. Eng. Chem. Res. 2019, 58 (22), 9596-9606.

(6) Preturlan, J. G. D.; Vieille, L.; Quiligotti, S.; Favergeon, L. Comprehensive Thermodynamic Study of the Calcium Sulfate-Water Vapor System. Part 2: Physical Modeling of Adsorption Phenomena. Ind. Eng. Chem. Res. 2019, 58 (22), 9607-9616.

(7) Kamitsos, E. I.; Karakassides, M. A.; Chryssikos, G. D. A Vibrational Study of Lithium Sulfate Based Fast Ionic Conducting Borate Glasses. J. Phys. Chem. 1986, 90 (19), 4528-4533.

(8) Yu, N.; Wang, R. Z.; Wang, L. W. Sorption Thermal Storage for Solar Energy. Prog. Energy Combust. Sci. 2013, 39 (5), 489-514.

(9) N'Tsoukpoe, K. E.; Schmidt, T.; Rammelberg, H. U.; Watts, B. A.; Ruck, W. K. L. A Systematic Multi-Step Screening of Numerous Salt Hydrates for Low Temperature Thermochemical Energy Storage. Appl. Energy 2014, 124, 1-16. 
(10) Yan, T.; Wang, R. Z.; Li, T. X.; Wang, L. W.; Fred, I. T. A Review of Promising Candidate Reactions for Chemical Heat Storage. Renew. Sustain. Energy Rev. 2015, 43, $13-31$.

(11) Okhrimenko, L.; Favergeon, L.; Johannes, K.; Kuznik, F.; Pijolat, M. Thermodynamic Study of $\mathrm{MgSO}_{4}-\mathrm{H}_{2} \mathrm{O}$ System Dehydration at Low Pressure in View of Heat Storage. Thermochim. Acta 2017, 656, 135-143.

(12) McAdie, H. G. The Effect of Water Vapor upon the Dehydration of $\mathrm{CaSO}_{4} \cdot 2 \mathrm{H}_{2} \mathrm{O}$. Can. J. Chem. 1964, 42, 792-801.

(13) Kuntze, R. A. Effect of Water Vapor on the Formation of $\mathrm{CaSO}_{4} \cdot 1 / 2 \mathrm{H}_{2} \mathrm{O}$ Modifications. Can. J. Chem. 1965, 43 (6), 2522-2529.

(14) Ball, M. C.; Norwood, L. S. Studies in the System Calcium Sulphate-Water. Part I. Kinetics of Dehydration of Calcium Sulphate Dihydrate. J. Chem. Soc. A Inorg. Physic Theory 1969, 1633-1637.

(15) Koga, N.; Suzuki, Y.; Tatsuoka, T. Thermal Dehydration of Magnesium Acetate Tetrahydrate: Formation and in Situ Crystallization of Anhydrous Glass. J. Phys. Chem. B 2012, 116 (49), 14477-14486.

(16) Valdivieso, F.; Bouineau, V.; Pijolat, M.; Soustelle, M. Kinetic Study of the Dehydration of Lithium Sulphate Monohydrate. Solid State Ionics 1997, 101-103, 1299-1303.

(17) Favergeon, L.; Pijolat, M. Influence of Water Vapor Pressure on the Induction Period during $\mathrm{Li}_{2} \mathrm{SO}_{4} \cdot \mathrm{H}_{2} \mathrm{O}$ Single Crystals Dehydration. Thermochim. Acta 2011, 521 (1-2), $155-160$.

(18) Koga, N.; Favergeon, L.; Kodani, S. Impact of Atmospheric Water Vapor on the Thermal Decomposition of Calcium Hydroxide: A Universal Kinetic Approach to a PhysicoGeometrical Consecutive Reaction in Solid-Gas Systems under Different Partial Pressures of Product Gas. Phys. Chem. Chem. Phys. 2019, 21 (22), 11615-11632. 
(19) Ogasawara, H.; Koga, N. Kinetic Modeling for Thermal Dehydration of Ferrous Oxalate Dihydrate Polymorphs: A Combined Model for Induction Period-Surface ReactionPhase Boundary Reaction. J. Phys. Chem. A 2014, 118 (13), 2401-2412.

(20) Koga, N.; Tanaka, H. Kinetic and Morphological Studies of the Thermal Dehydration of. Alpha.-Nickel (II) Sulfate Hexahydrate. J. Phys. Chem. 1994, 98 (41), 10521-10528.

(21) Fukuda, M.; Favergeon, L.; Koga, N. A Universal Kinetic Description for Thermal Decomposition of Copper(II) Hydroxide over Different Water Vapor Pressures. J. Phys. Chem. C 2019, 123 (34), 20903-20915.

(22) Iwasaki, S.; Koga, N. Thermal Dehydration of Calcium Sulfate Dihydrate: PhysicoGeometrical Kinetic Modeling and the Influence of Self-Generated Water Vapor. Phys. Chem. Chem. Phys. 2020, 22, 22436-22450.

(23) Sharp, J. H.; Brindley, G. W.; Achar, B. N. N. Numerical Data for Some Commonly Used Solid State Reaction Equations. J. Am. Ceram. Soc. 1966, 49 (7), 379-382.

(24) Pijolat, M.; Favergeon, L. Kinetics and Mechanisms of Solid-Gas Reactions. In Handbook of Thermal Analysis and Calorimetry; 2018; Vol. 6, pp 173-212.

(25) Koga, N. Physico-Geometric Approach to the Kinetics of Overlapping Solid-State Reactions. In Handbook of Thermal Analysis and Calorimetry; Elsevier B.V., 2018; Vol. 6, pp 213-251.

(26) Pijolat, M.; Valdivieso, F.; Soustelle, M. Experimental Test to Validate the Rate Equation "D $\alpha / \mathrm{Dt}=\mathrm{Kf}(\alpha)$ " Used in the Kinetic Analysis of Solid State Reactions. Thermochim. Acta 2005, 439 (1-2), 86-93.

(27) Pijolat, M.; Favergeon, L.; Soustelle, M. From the Drawbacks of the Arrhenius-f( $\alpha$ ) Rate Equation towards a More General Formalism and New Models for the Kinetic Analysis of Solid-Gas Reactions. Thermochim. Acta 2011, 525 (1-2), 93-102.

(28) Pijolat, M.; Soustelle, M. Experimental Tests to Validate the Rate-Limiting Step 
Assumption Used in the Kinetic Analysis of Solid-State Reactions. Thermochim. Acta 2008, 478, 34-40.

(29) Galwey, A. K.; Brown, M. E. Application of the Arrhenius Equation to Solid State Kinetics: Can This Be Justified? Thermochim. Acta 2002, 386 (1), 91-98.

(30) Galwey, A. K. Is the Science of Thermal Analysis Kinetics Based on Solid Foundations?: A Literature Appraisal. Thermochim. Acta 2004, 413 (1-2), 139-183.

(31) Soustelle, M. Handbook of Heterogeneous Kinetics; ISTE Editions Ltd and John Wiley \& Sons, Inc, 2010.

(32) Kodani, S.; Iwasaki, S.; Favergeon, L.; Koga, N. Revealing the Effect of Water Vapor Pressure on the Kinetics of Thermal Decomposition of Magnesium Hydroxide. Phys. Chem. Chem. Phys. 2020.

(33) Yamamoto, Y.; Favergeon, L.; Koga, N. Thermal Dehydration of Lithium Sulfate Monohydrate Revisited with Universal Kinetic Description over Different Temperatures and Atmospheric Water Vapor Pressures. J. Phys. Chem. C 2020, 124 (22), 1196011976.

(34) Criado, J. M.; González, M.; Málek, J.; Ortega, A. The Effect of the $\mathrm{CO}_{2}$ Pressure on the Thermal Decomposition Kinetics of Calcium Carbonate. Thermochim. Acta 1995, 254, $121-127$.

(35) Vyazovkin, S.; Burnham, A. K.; Criado, J. M.; Pérez-Maqueda, L. A.; Popescu, C.; Sbirrazzuoli, N. ICTAC Kinetics Committee Recommendations for Performing Kinetic Computations on Thermal Analysis Data. Thermochim. Acta 2011, 520 (1-2), 1-19.

(36) Liavitskaya, T.; Vyazovkin, S. Delving into the Kinetics of Reversible Thermal Decomposition of Solids Measured on Heating and Cooling. J. Phys. Chem. C 2017, 121 (28), 15392-15401.

(37) Koga, N.; Tanaka, H. A Physico-Geometric Approach to the Kinetics of Solid-State 
Reactions as Exemplified by the Thermal Dehydration and Decomposition of Inorganic Solids. Thermochim. Acta 2002, 388 (1-2), 41-61.

(38) Neveux, L.; Chiche, D.; Pérez-Pellitero, J.; Favergeon, L.; Gay, A. S.; Pijolat, M. New Insight into the $\mathrm{ZnO}$ Sulfidation Reaction: Mechanism and Kinetics Modeling of the $\mathrm{ZnS}$ Outward Growth. Phys. Chem. Chem. Phys. 2013, 15 (5), 1532-1545.

(39) Viricelle, J.; Pijolat, M.; Soustelle, M. Transformation of Cerium(Iii) Hydroxycarbonate into Ceria. Part 1.-Nucleation and Growth Rates of Ceria. J. Chem. Soc. Faraday Trans. 1995, 91 (24), 4431-4435.

(40) Viricelle, J.; Pijolat, M.; Soustelle, M. Transformation of Cerium(Iii) Hydroxycarbonate into Ceria. Part 2.- Eperimental Study of the Growth Rate. J. Chem. Soc. Faraday Trans. 1995, 91 (24), 4437-4440.

(41) Rouchon, L.; Favergeon, L.; Pijolat, M. Analysis of the Kinetic Slowing down during Carbonation of $\mathrm{CaO}$ by $\mathrm{CO}_{2}$. J. Therm. Anal. Calorim. 2013, 113 (3), 1145-1155.

(42) Mansour, M.; Favergeon, L.; Pijolat, M. Kinetic Modeling of Low Temperature Oxidation of Copper Nanoparticles by $\mathrm{O}_{2}$. Thermochim. Acta 2013, 570, 41-50.

(43) Galai, H.; Pijolat, M.; Nahdi, K.; Trabelsi-Ayadi, M. Mechanism of Growth of MgO and CaCO3 during a Dolomite Partial Decomposition. Solid State Ionics 2007, 178 (15-18), $1039-1047$.

(44) Serris, E.; Favergeon, L.; Pijolat, M.; Soustelle, M.; Nortier, P.; Gärtner, R. S.; Chopin, T.; Habib, Z. Study of the Hydration of $\mathrm{CaO}$ Powder by Gas-Solid Reaction. Cem. Concr. Res. 2011, 41 (10), 1078-1084.

(45) Strydom, C. A.; Hudson-Lamb, D. L.; Potgieter, J. H.; Dagg, E. The Thermal Dehydration of Synthetic Gypsum. Thermochim. Acta 1995, 269/270, 631-638.

(46) Ball, M. C.; Urie, R. G. Studies in the System Calcium Sulphate-Water. Part II. The Kinetics of Dehydration of $\mathrm{B}-\mathrm{CaSO}_{4}, 1 / 2 \mathrm{H}_{2} \mathrm{O}$. J. Chem. Soc. A Inorg. Physic Theory 
1970, 528-530.

(47) Gardet, J. J. Hydrates Non Stoechiométriques: Réactions de Déshydratation Du Sulfate de Calcium et de l'oxalate de Manganese à Deux Molécules d'eau, Université Scientifique et Médicale de Grenoble, 1974.

(48) Ball, M. C.; Norwood, L. S. Studies in the System Calium Sulphate-Water. Part III. Kinetics of Dehydration of $\alpha$-Calcium Sulphate Hemihydrate. J. Chem. Soc. A Inorg. Physic Theory 1970, 1476-1479.

(49) Cave, S.; Holdich, R. G. The Dehydration Kinetics of Gypsum in a Fluidized Bed Reactor. Trans. Inst. Chem. Eng. 2000, 78, 971-978.

(50) Galwey, A. K.; Brown, M. E. Thermal Decomposition of Ionic Solids; Amsterdam: Elsevier, 1999.

(51) Avrami, M. Kinetics of Phase Change. I: General Theory. J. Chem. Phys. 1939, 7 (12), $1103-1112$

(52) Avrami, M. Kinetics of Phase Change. II Transformation-Time Relations for Random Distribution of Nuclei. J. Chem. Phys. 1940, 8 (2), 212-224.

(53) Avrami, M. Kinetics of Phase Change. III: Granulation, Phase Change, and Microstructure. J. Chem. Phys. 1941, 9 (2), 177-184.

(54) Brunauer, S.; Emmett, P. H.; Teller, E. Adsorption of Gases in Multimolecular Layers. J. Am. Chem. Soc. 1938, 60 (2), 309-319.

(55) Barrett, E. P.; Joyner, L. G.; Halenda, P. P. The Determination of Pore Volume and Area Distributions in Porous Substances. I. Computations from Nitrogen Isotherms. J. Am. Chem. Soc. 1951, 73 (1), 373-380.

(56) Rouquerol, F.; Rouquerol, J.; Sing, K. Adsorption by Powder and Porous Solids: Principles, Methodology and Applications; Academic Press, 1999.

(57) Huber, M. L.; Harvey, A. H. Thermal Conductivity of Gases. In CRC Handbook of 
Chemistry and Physics; CRC-Press: Boca Raton, FL, USA, 2011.

(58) Vyazovkin, S.; Chrissafis, K.; Di Lorenzo, M. L.; Koga, N.; Pijolat, M.; Roduit, B.; Sbirrazzuoli, N.; Suñol, J. J. ICTAC Kinetics Committee Recommendations for Collecting Experimental Thermal Analysis Data for Kinetic Computations. Thermochim. Acta 2014, 590, 1-23.

(59) Kelley, K. K.; Southard, J. C.; Anderson, C. T. Thermodynamic Properties of Gypsum and Its Dehydration Products. Bur. Mines, United States Dep. Inter. 1941, 1-74.

(60) Bezou, C.; Nonat, A.; Mutin, J. C.; Nørlund Christensen, A.; Lehmann, M. S. Investigation of the Crystal Structure of $\gamma-\mathrm{CaSO}_{4}, \mathrm{CaSO}_{4} \cdot 0.5 \mathrm{H}_{2} \mathrm{O}$, and $\mathrm{CaSO}_{4} \cdot 0.6 \mathrm{H}_{2} \mathrm{O}$ by Powder Diffraction Methods. Journal of Solid State Chemistry. 1995, pp 165-176.

(61) Favergeon, L.; Pijolat, M.; Valdivieso, F.; Helbert, C. Experimental Study and MonteCarlo Simulation of the Nucleation and Growth Processes during the Dehydration of Li2SO4·H2O Single Crystals. Phys. Chem. Chem. Phys. 2005, 7 (21), 3723.

(62) Fusseis, F.; Schrank, C.; Liu, J.; Karrech, A.; Llana-Fúnez, S.; Xiao, X.; Regenauer-Lieb, K. Pore Formation during Dehydration of a Polycrystalline Gypsum Sample Observed and Quantified in a Time-Series Synchrotron X-Ray Micro-Tomography Experiment. Solid Earth 2012, 3 (1), 71-86.

(63) Bedford, J.; Fusseis, F.; Leclère, H.; Wheeler, J.; Faulkner, D. A 4D View on the Evolution of Metamorphic Dehydration Reactions. Sci. Rep. 2017, 7 (1), 1-7.

(64) Sipple, E. M.; Bracconi, P.; Dufour, P.; Mutin, J. C. Microstructural Modifications Resulting from the Dehydration of Gypsum. Solid State Ionics 2001, 141-142, 447-454.

(65) Koga, N.; Kimizu, T. Thermal Decomposition of Indium(III) Hydroxide Prepared by the Microwave-Assisted Hydrothermal Method. J. Am. Ceram. Soc. 2008, 91 (12), 40524058.

(66) Kimura, T.; Koga, N. Thermal Dehydration of Monohydrocalcite: Overall Kinetics and 
Physico-Geometrical Mechanisms. J. Phys. Chem. A 2011, 115 (38), 10491-10501.

(67) Fukuda, M.; Koga, N. Kinetics and Mechanisms of the Thermal Decomposition of Copper(II) Hydroxide: A Consecutive Process Comprising Induction Period, Surface Reaction, and Phase Boundary-Controlled Reaction. J. Phys. Chem. C 2018, 122 (24), $12869-12879$.

(68) Kitabayashi, S.; Koga, N. Thermal Decomposition of Tin(II) Oxyhydroxide and Subsequent Oxidation in Air: Kinetic Deconvolution of Overlapping Heterogeneous Processes. J. Phys. Chem. C 2015, 119 (28), 16188-16199.

(69) Mampel, K. L. Zeitamsatzformeln Für Heterogene Reaktionen. Zeitschrift fur Phys. Chemie A 1940, 187, 43-57.

(70) Mampel, K. L. Zeitamsatzformeln Für Heterogene Reaktionen. Zeitschrift fur Phys. Chemie A 1940, 187 (1), 235-249.

(71) Delmon, B. Introduction à La Cinétique Hétérogène; Éditions Technip, 1969.

(72) Bouineau, V.; Pijolat, M.; Soustelle, M. Characterisation of the Chemical Reactivity of a $\mathrm{CaCO}_{3}$ Powder for Its Decomposition. J. Eur. Ceram. Soc. 1998, 18 (9), 1319-1324.

(73) Favergeon, L.; Morandini, J.; Pijolat, M.; Soustelle, M. A General Approach for Kinetic Modeling of Solid-Gas Reactions at Reactor Scale: Application to Kaolinite Dehydroxylation. Oil Gas Sci. Technol. - Rev. d'IFP Energies Nouv. 2013, 68 (6), 10391048.

(74) Favergeon, L.; Pijolat, M.; Soustelle, M. Surface Nucleation and Anisotropic Growth Models for Solid-State Reactions. Thermochim. Acta 2017, 654 (May), 18-27.

(75) Helbert, C.; Touboul, E.; Perrin, S.; Carraro, L.; Pijolat, M. Stochastic and Deterministic Models for Nucleation and Growth in Non-Isothermal and/or Non-Isobaric Powder Transformations. Chem. Eng. Sci. 2004, 59 (7), 1393-1401.

(76) Kärger, J.; Ruthven, D. M.; Theodorou, D. N. Diffusion in Nanoporous Materials, 1st 
Ed.; Wiley-VCH, 2012.

(77) Naumov, S.; Valiullin, R.; Monson, P. A.; Kärger, J. Probing Memory Effects in Confined Fluids via Diffusion Measurements. Langmuir 2008, 24 (13), 6429-6432.

(78) Kröger, F. A. The Chemistry of Imperfect Crystals; Wiley-VCH: Amsterdam, 1964.

(79) Favergeon, L.; Pijolat, M.; Helbert, C. A Mechanism of Nucleation during Thermal Decomposition of Solids. J. Mater. Sci. 2008, 43 (14), 4675-4683. 
TOC GRAPHIC

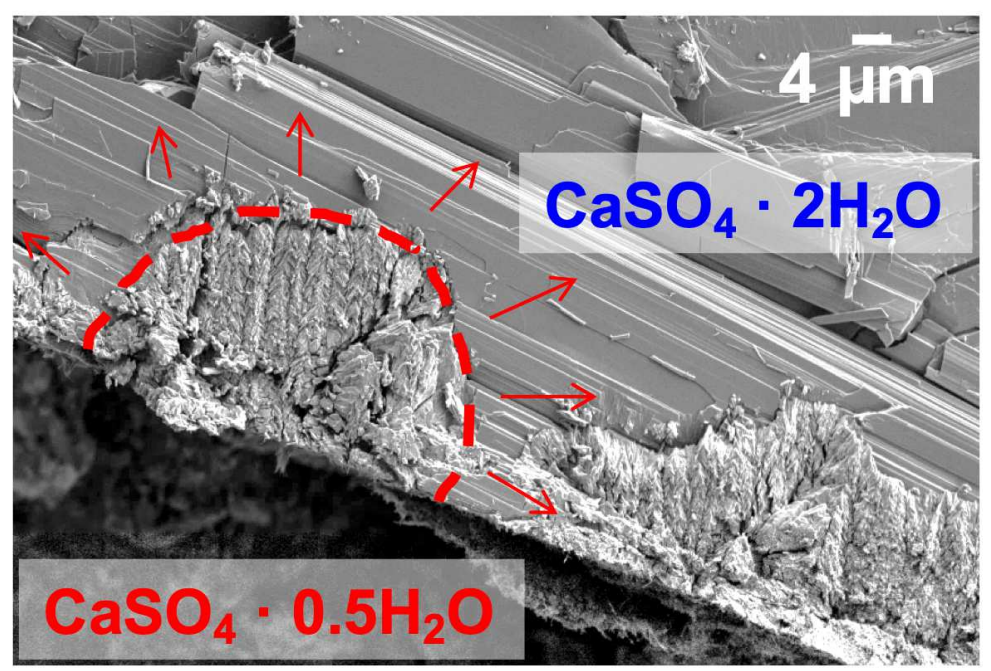

